\title{
Forensic anthropology and human identification
}

\author{
Niels Lynnerup
}

Unit of Forensic Anthropology, Dept of Forensic Medicine, Frederik d. 5's Vej 11, DK-2100 Copenhagen, Denmark

\author{
ABSTRACT \\ This is the full summary paper of a thesis to be defended at the University of Copenhagen, May $31^{\text {st }}, 2013$. \\ Keywords: \\ Human Identification, Ageing, Sex determination, Ethnicity, Skeletal features.
}

\section{INTRODUCTION}

Forensic anthropology may be defined as the application of biological or physical anthropology in the service of justice [1]. The main issue in forensic anthropology is human identification, most often of human remains. Forensic anthropological identification of human skeletonised remains is most often based on assessing the age at death, sex, stature, and individual traits. Thus, in a Danish setting at least, forensic anthropological techniques are usually applied as supporting and supplementary methods, with final identification ultimately being based on forensic odontological analyses [2], fingerprinting, and DNA-techniques [3]. In a few instances, forensic anthropological methods may also by themselves achieve identification, when specific and individual skeletal traits may be compared to verifiable medical records and images, e.g., frontal sinus morphology [4].

Many forensic anthropological methods for aging and sexing have been around for some time, some more than a hundred years, and form part of the basic forensic anthropological toolbox [see, e.g., 5-8]. These methods generally rely on identifying certain age- or sex-related morphological skeletal traits, then setting these traits in a system of stages or scores, which then results in an estimated age interval. But there are inherent problems in this approach:

- First, a given method needs to be so well-defined or explained that it does not entail undue intra- or inter-observer error when applied. There have been several published methods, which indicated a good agreement between certain morphological stages, but which only seemed to work for the proponent: other studies by other observers did not achieve same agreement. Since the results of a forensic anthropological analysis may wind up in court, it is obviously important that the degree of observer variation must be quantified. Continued assessment of the validity of the method, including intra- and inter-observer assessments are therefore important [8].

- Secondly, there is the problem of how a given method, developed on a specific reference sample, translates to other populations. Can a method developed using a 100-years old anatomical collection in one country, be readily used in modern forensic cases in another country? There may further be the need of modification or development of methods due to taphonomic processes and other circumstances.
The present work has mainly addressed these two issues. The Papers II, XI and XIII explicitly deal with assessing observer variation. It is our contention that not only may the observer variation be large, but that observer variation is often not addressed fully, and if addressed then with un-sufficient statistics. A high coefficient of correlation or a significance test may be given as indicative for small observer variation, even though in fact the variation may be quite large. One of the reasons for the continuous find of a rather large observer variation, and the lack of precision of many of the methods used in forensic anthropology, is due to the difficulty of describing an anatomical structure in a quantifiable way. Paper $\mathbf{V I}$ is an attempt to look at a well-known trait, cranial sutures, but by using fractal geometry, while Paper $\mathbf{X}$ conversely tries to apply a very simplified approach for determining the diameter of a complex structure, the internal acoustic meatus.

The second problem of translating methods to other populations is addressed in Papers III, V, VII, VIII and IX. In a forensic setting one obviously needs to know whether certain methods are applicable, even though the methods were developed on entirely different populations. As for modifications, Paper I is a study of how one established method, developed on radiography of macerated bones, works on un-macerated bones.

Finally, aside looking critically at already developed methods, there is the need to devise new methods. The more methods there are in the forensic anthropological toolbox, the better prepared the forensic anthropologist will be. Given the abovementioned problems in quantifying complicated biological structures and traits, it would be of special interest to develop methods which do not rely on these but on biochemical or nuclear physical markers, which may be measured with high precision. Paper $\mathbf{X I}$ relates to a study on protein racemisation, while Papers XII and XIV describe a novel method for ascertaining age by measuring ${ }^{14} \mathrm{C}$ content of eye lens proteins.

The papers forming this review also reflect the wide range of techniques used in forensic anthropology: direct morphoscopy (Paper IX) and morphometry (Papers V-X), including the use of histology (Papers II and XI) and radiography (Papers I, III and XIII), as well as biochemical (Paper XII) and nuclear physical methods (Papers XII and XIV).

The papers constituting this thesis are presented under the headings of the basic questions the forensic anthropologist is asked: what is the age, sex and ethnicity? This thesis is thus focused on critically assessing and developing physical anthropological methods in order to address these questions. 


\section{AGE EVALUATION}

A fundamental presupposition of most forensic anthropological methods is that the biological age of an individual more or less follows the chronological age. The chronological age is our calendar age, the age by which we identify our age in years, while the biological age refers to how aging affects our body, and how this may be observed. While soft tissue may be present, forensic age determination is in all practicality based on dental or skeletal traits. Aging phenomena obviously also occurs in non-bony tissues, but these are more difficult to discern or tabulate in a useful way compared to odontological and skeletal age-related traits. Aging of the living, e.g. determining if an individual is of legal age, is also often based solely on (radiological) dental and skeletal examination [8] (specifically also in Denmark [9]). Methods which one way or the other rely on interpretation of skeletal morphology are in this review termed conventional methods, while biochemical and nuclear physical methods are termed absolute methods.

\subsection{Conventional methods}

Assessing the age when dealing with subadults may be done somewhat reliably, as the biological - chronological relationship is clearly reflected in the subadult, growing skeleton. Thus, features associated with bone growth, such as epiphyseal closure [6,10-12], closure of the sphenobasilar synchondrosis [6], and (diaphyseal) bone length $[10,12,13]$ may be used.

Concerning the adult skeleton, most methods focus on the non-synovial joints. Changes in the bone joint surfaces have been tabulated and related to broad age categories, typically ranging 10 years or more $[5,6,10,14]$. Non-synovial joints are found between the three bones making up the pelvis: the (two) sacro-iliac joint(s) between the inominate and sacrum, and the symphyseal joint between the two inominates. Generally, both joints exhibit the same changes, in that an undulating surface gradually becomes porotic and pitted with loss of the undulating pattern, as well as developing a more pronounced demarcation of the joint surface from the surrounding bone. Several methods have been described to evaluate these changes, and hence relate this evaluation, usually by identifying a certain stage, to an age interval. Lovejoy et al. [15] described a method for the auricular surface of the inominate (the sacroiliac joint), which has since been modified, most recently by Buckberry and Chamberlain [16] The symphyseal surface has a long history, a method first being published by Todd in 1920 [17], with several revisions since, e.g by Suchey and coworkers (e.g. [18]. Another non-synovial joint is the joint between the sternal rib end and the rib cartilage. Iscan et al. [20] first published a method whereby age-related changes could be observed, generally being a result of a rather clear cut demarcation between bone and cartilage being rendered more uneven due to bony out growth and bone thinning, with age. Synovial joints may also be used to evaluate age in the sense that the development of arthrosis may give an indication of age [21]. While arthrosis clinically is age related, it is also related to numerous other things, such as genetic make-up, nutrition, and biomechanical loading [e.g., 22]. A scoring system for, e.g., the degree of lipping on vertebral margins has been published by Stewart [11].

In the following papers we examined and tested several of the abovementioned methods.

\subsubsection{Sutures [Paper VI]}

One of the oldest methods in forensic anthropology relies on the cranial sutures, again non-synovial joints (synostoses). Described by Broca in 1875, it has since been tested extensively, although with the overall finding that even though there seems to be an age-related trend in the complete ossification of the sutures, seen as obliteration, this trend is perhaps more tenuous than for the other methods described above [e.g., 12,23-26]. It has been difficult to develop unbiased and definite criteria for using the sutures in age determination [24-27].

This may be due to an at best tenuous relationship between sutural ossification and age. We suggested that it may also be due to the difficulties of quantifying a highly variable, 2-dimensional structure as the cranial suture (as seen either ecto- or endocranially). Different methods of scoring are usually applied when physical anthropologists quantify suture obliteration [e.g., 25-27]. Such scoring systems may be rather subjective, both in terms of the exact location where a suture is to be scored, in the definitions of the various scores, and finally in their classification, typically on a limited, rank ordered, non-parametric scale. Since the suture may be viewed as a highly convoluted line, sometimes with partial or even complete obliteration (Figure 1), we thought that the methods of fractal geometry may yield a better descriptor [28]. Fractal geometry seeks to address highly irregular structures, and is basically a powerful method for comparing the spatial complexity of real objects [29] The fractal dimension (FD) of a cranial suture is a natural fractal $[28,30]$.

We calculated the fractal dimensions of human sagittal and coronal sutures on 31 complete skulls from the Terry collection at the Smithsonian Institution, Washington, D.C. The fractal dimension was calculated using the box-counting technique [31]. However, the fractal dimension did not yield better age correlations than other previously described methods (Table 1). At best, the results reflected the general observation that young adults below 40 years of age do display an age related development, but that it

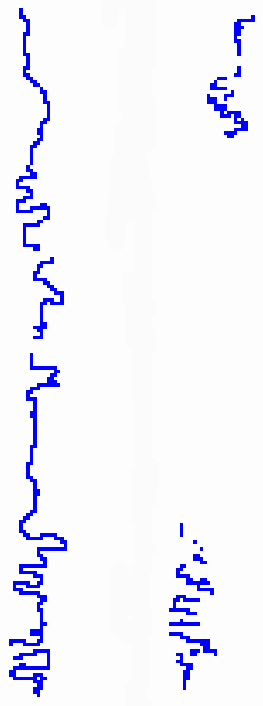

Figure 1. Sagitttal suture tracings showing convoluted pattern. The left suture is of a 27 -year old male, $F D=1.116$. The right suture is of a 78 -year old male, $\mathrm{FD}=1.144$. Even though the suture of the older person is clearly more obliterated, the FD is nearly the same, due to segments of nearly identical complexity. 
is impossible to arrive at any precise age determinations for older adults (see Figure 2). It seems that for some individuals, suture obliteration simply does not take place even in high age, whereas for others, suture obliteration progresses rapidly. Until a better understanding of sutural biology is reached, this will render cranial sutures only marginally useful in age determination. This does not mean though, that investigations should not be made to elucidate fractal geometrical methods of sutural morphology quantification [32,33].

\subsubsection{Microscopic methods [Papers II, XI]}

In 1965 Kerley described a method of determining the age at death by counting the secondary osteons, osteon fragments, nonHaversian canals and the percentage of lamellar bone from the midshaft of the femur, tibia and fibula [34]. Other workers have since modified and changed the method [35-44].The assessment of microscopical features in cross sections of the femur (or other bones) is considered a well established method, and several studies have investigated the effects of differing preservation, disease processes [4549], as well as, e.g., the importance of sampling location (proximally or distally on the bone) $[39,50]$. However, even though the method was described forty years ago, we found that there were two significant problems present at the very foundations of the method: 1) the diverging and subjective definitions of the used histological features (secondary osteons, non-Haversian canals and fragments, and in some studies also assessment of lamellar bone); and 2) the non-random choice of the region of interest within a bone cross section where these features are to be quantified.

Only few of the published articles that we know of, have reviewed or examined the intra- and inter-observer variation of the various microscopical methods $[37,46,51]$. Apart from the problem of sporadic observer variation studies, there are also problems in the applied statistics and sometimes only a correlation coefficient is calculated to describe observer agreement. This is inadequate; if one observer for each case only counts half as many osteon

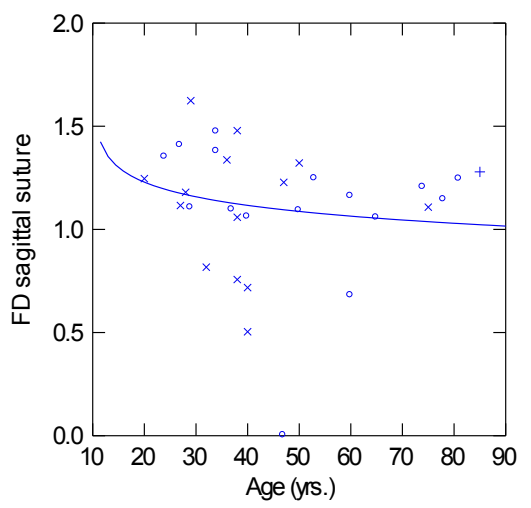

fragments as another observer for the same cases, their correlation coefficient may well be extremely close to 1 , yet clearly their results are completely different. Likewise, statistical testing for significant differences (usually at a significance level of 0.05 ) are not wholly adequate, as even results with large differences may not necessarily display statistical significance [e.g. 51]. What is needed is a quantification of the differences, so that other researchers can assess whether the differences, significant or not, are too large to warrant the method being used. The applied statistical analyses we used followed the procedure outlined by Bland and Altman [52]. First, a graphical expression of the intra and inter observer agreement was produced by plotting the data including the "line of equality", i.e., a line on which all points would lie if there was complete agreement between the observations (Figure 3). The agreement was further analysed by plotting the difference against the mean (Figure 4). In this way, a graphical representation is obtained both of the span in variation, and of the possible heterogeneity of the observer variation as a function of the osteon count. The mean difference of all the counts, which ideally should be 0 , can be calculated and shown as a horizontal line. The span in the variation is quantified by plotting the "limits of agreement", i.e., the mean difference (d) plus/minus two standard deviations ( $\pm 2 \mathrm{~s}$ ) (Figure 4).

The inter-observer analyses showed that the error was of almost the same magnitude as for the intra-observer error (not shown here). Figure 3 shows that osteon fragment counts display the largest variation between the three observers. If, e.g., Observer I counts 50 osteons in a given case, then Observer II's count of the same specimen will lie in the range of 36 to 64 osteons in $95 \%$ of the trials ( $50 \pm 13.892$; Table 2 ). Even more significant is the difference concerning the osteon fragments: e.g., if Observer I counts 60 osteon fragments in a given case, Observer III's count will lie in the range of 16 to 104 fragments in $95 \%$ of the trials $(60 \pm 44.190$; Table 2$)$. Thus, the limits of agreement, especially for fragments are wide. Yet, the Spearman correlation coefficients for the osteon fragment counts are all in the range of $0.63-0.93$.

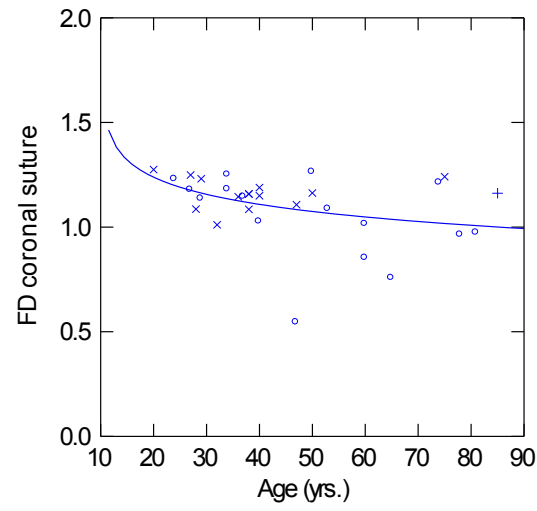

Figure 2. Scatterplots of saggital suture FD and coronal suture FD, respectively, versus actual age-at-death. Log smoother inlaid in plots $(O=$ females; $X=$ males $)$.

Table 1. Medians, means and range of fractal dimensions (FD) of sagittal and coronal sutures by sex, and Pearson correlation coefficients (r) with age..

\begin{tabular}{|c|c|c|c|c|c|c|c|c|}
\hline & \multicolumn{4}{|c|}{ FD Sagittal } & \multicolumn{4}{|c|}{ FD Coronal } \\
\cline { 2 - 9 } & Median & Mean & Range & $r$ & Median & Mean & Range & $r$ \\
\hline Female & 1.152 & 1.106 & $0.000-1.473$ & -0.164 & 1.110 & 1.049 & $0.543-0.262$ & -0.391 \\
\hline Male & 1.180 & 1.118 & $0.504-1.624$ & 0.034 & 1.159 & 1.161 & $1.011-1.275$ & 0.036 \\
\hline
\end{tabular}


Table 2. Mean difference between counts (d) and two standard deviations (2s) for each element. Values plotted as horizontal lines in Figure 4.

\begin{tabular}{|c|c|c|c|c|c|c|}
\hline & \multicolumn{2}{|c|}{ Observer I vs. II } & \multicolumn{2}{|c|}{ Observer I vs. III } & \multicolumn{2}{|c|}{ Observer II vs. III } \\
\hline & $d$ & $2 s$ & $d$ & $2 s$ & $d$ & $2 s$ \\
\hline Sec. osteons & 1.007 & 13.892 & -1.438 & 13.946 & -0.431 & 9.754 \\
\hline Hav. canals & 4.776 & 13.754 & -0.086 & 13.556 & 4.690 & 13.294 \\
\hline Osteon frag. & 10.414 & 27.454 & 2.741 & 44.190 & -7.720 & 36.494 \\
\hline
\end{tabular}

Observer I vs. II

Observer I vs. III
Observer II vs. III
Secondary Osteons
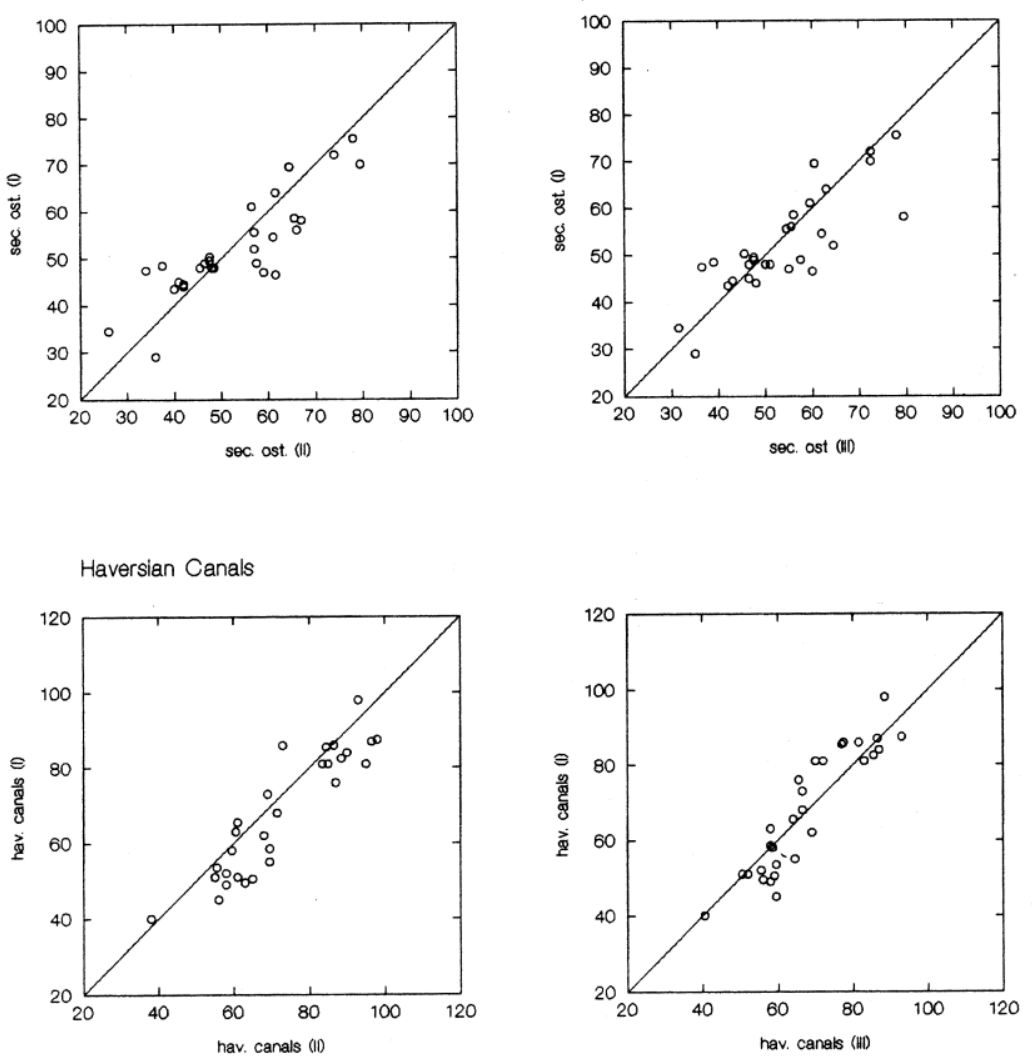

Osteon Fragments

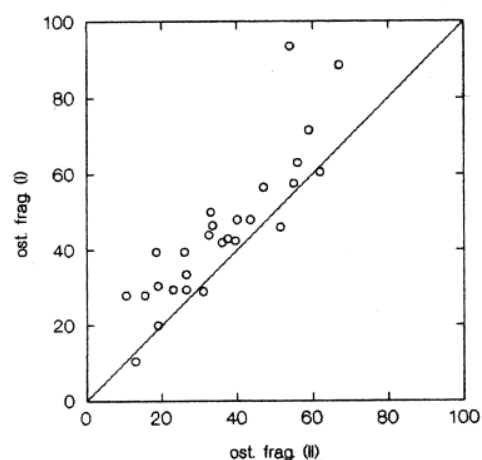

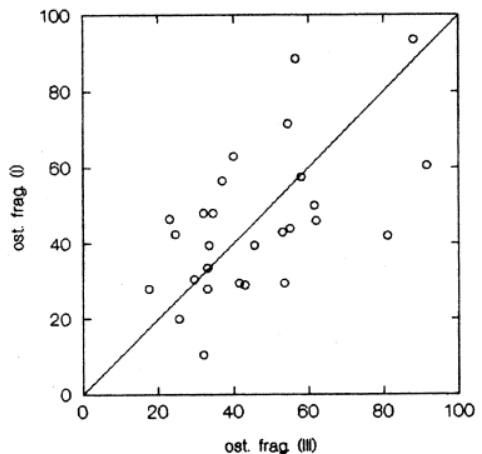
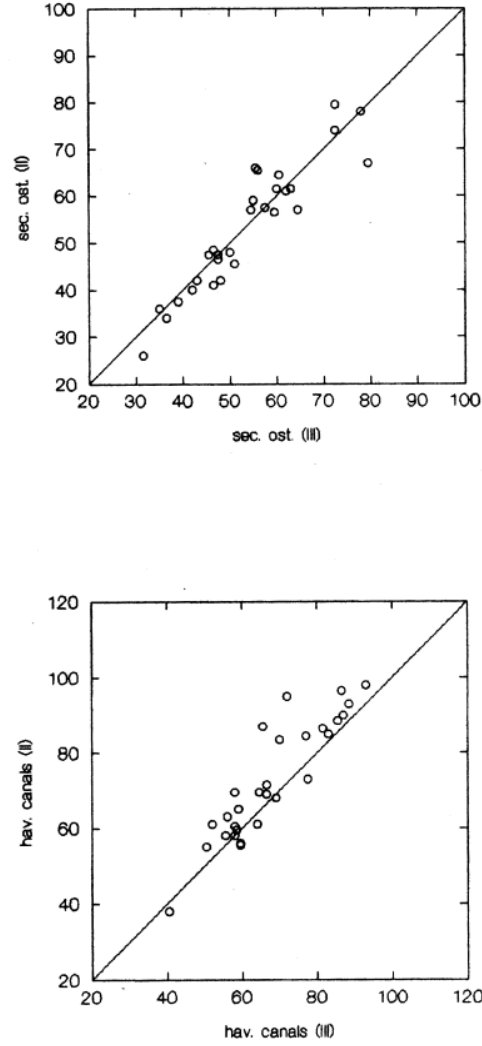

sec ost (ili)

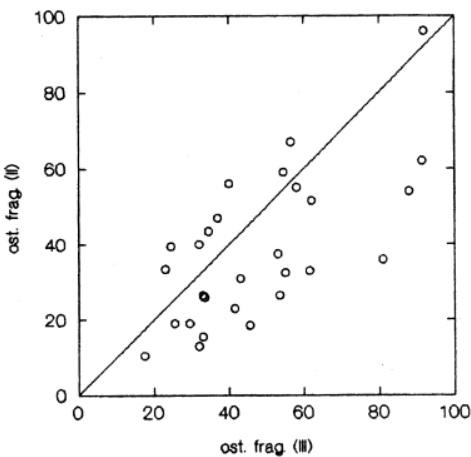

Figure 3. Inter-observer error for each of the three observer pairs (columns) for counts of secondary osteons, Haversian canals and osteon fragments (rows). The line of equality overlaid each plot. 
It seems that osteons can to some degree be identified reliably by all of the observers, and with a certain degree of agreement, but for both Haversian canals and fragments, the discrepancies are somewhat large. But our results also indicate that regression formulas using osteon fragment counts may result in higher error in the age estimate. This is unfortunate as especially osteon fragments are probably of some significance when dealing with older individuals, and excluding these elements from regression formulas would probably limit the histological methods to adults in the age range of 20 - 40 years. Rather than quantifying secondary osteons and osteon fragments per se, it has been suggested to add the counts of the two structures (representing the so-called osteon population density) [53,54]. However, this would only be an improvement if the "under counting" of one structure was more or less corrected by the "over counting" of the other and vice versa. Our study shows that the variation lies in the counting of
Observer I vs. II

Secondary Osteons

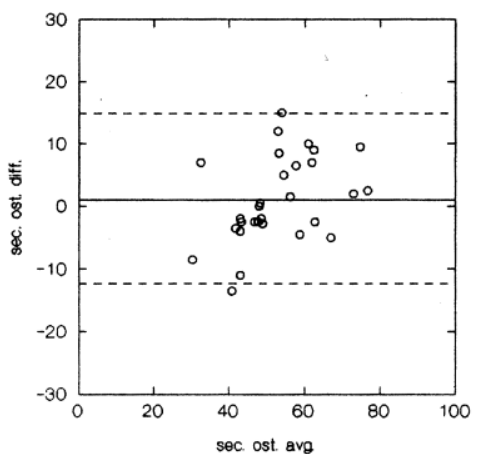

Haversian Canals

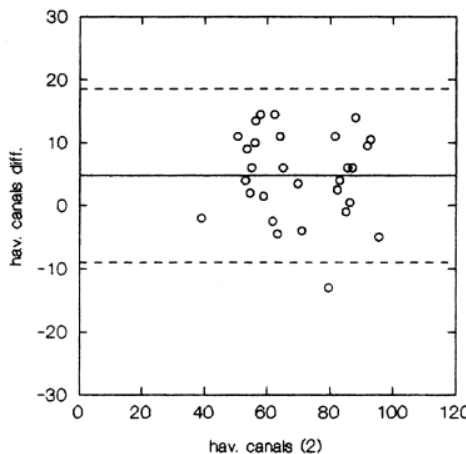

Osteon Fragments

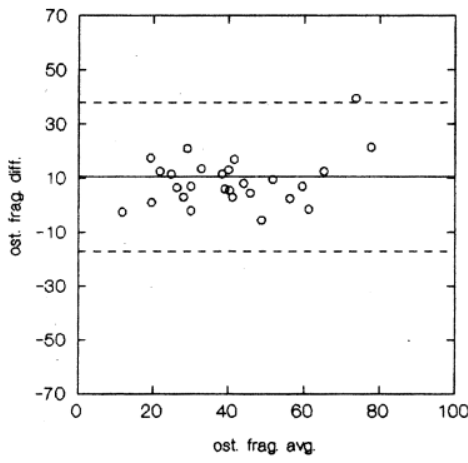

Observer I vs. III
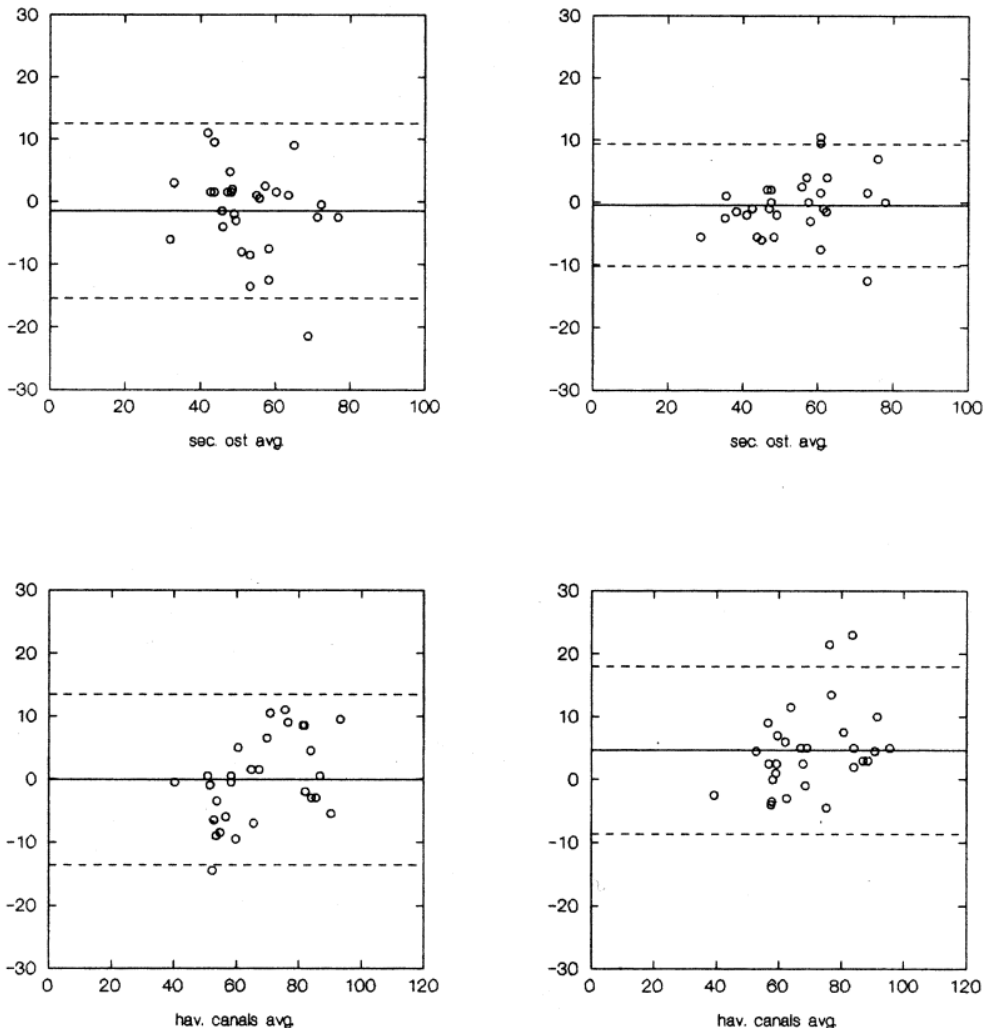

Observer II vs. III 
the fragments, while the secondary osteon counts are comparable. Clearly, adding one reliable parameter to an unreliable one does not result in a better and more reliable parameter.

It was interesting to note that the inter-observer variation is not much larger than the intra-observer variation, except for osteon fragments. This may suggest that even trained observers with extensive experience in osteon analysis have difficulty in assessing and counting the structures. Also, it is interesting that the structure which we a priori considered the most likely to exhibit the least variation, the Haversian canals, showed much variation, indeed more than for the secondary osteons, reflecting difficulties in differentiating between Haversian and non-Haversians elements. This indicates that clear and fundamental definitions on how to identify and delimit the structures are lacking. Prior to this study we did several detailed analyses and evaluations of bone tissue samples together, in order to develop consistent working definitions of the microscopic structures, along with an understanding of age related bone remodelling. We found, however, that beyond a certain point, it is simply not possible to differentiate between the structures. The delimiting structure of the osteon and the osteon fragment is the cement line, but even under powerful magnification this line may be difficult to differentiate from the cementing front in the secondary osteon, osteocyte canaliculi or artifacts caused by the preparation of the specimen. We tried to address this problem by various histological staining techniques [55], but in our opinion this did not improve the identification of the features, although other investigators have reported improvement with staining [53].

Not only may the single structures of interest be difficult to define; also defining the very regions of interest (ROI) were these structures should be analysed has posed problems. The arbitrary selection of ROls will introduce bias, both because the choosing of a these areas, following the published methods, is not done in a truly random fashion, and because the delineation of the area itself and how features on the area border are dealt with are unclear. The former may be dealt with by counting the histological features throughout the entire cross-section, without choosing sub sections. Counting all secondary osteons would be extremely timeconsuming. However, by applying stereological principles [56], an unbiased quantification of the histological features may not necessitate that all the features are counted throughout the entire section: it is necessary only to count within a subset of smaller fields, as long as these are chosen randomly, and as long as they result in approximately 100 to 200 counts of the feature in question [56].

In a first such study (but focusing only on secondary osteons), our approach was to visualise an entire femoral cross section in a $\mathrm{x} 2$ magnification on a flat panel LCD monitor. An entire cross-section measured approximately $6-8 \times 6-10 \mathrm{~cm}$. A grid was generated by the software and divided the screen, and hence the femoral cross-section, into quadrants of $2 \times 2 \mathrm{~cm}$. All grid intersections lying within the femoral section were then marked. A smaller grid, measuring $2.5 \times 1.4 \mathrm{~mm}$ was then overlaid the image, and all quadrants within this grid, which included a marker from the first grid points, where selected as ROIs for counting the secondary osteons. ROIs were excluded if they were partly devoid of bone because of the endosteal or periosteal edge (Figure 5). This process meant that selection of the ROIs was made in a random fashion, and that between 7 and 18 (median $=11.5$ ) ROls were selected for each cross-section, meaning that at least 100 secondary osteons would be counted for each section. The fundamental stereological prerequisites for inferring the total number of histological elements for an entire section are thus met [56]. The exact measurements and proportions of the grids and ROls do not have to be equal throughout the sampling, as long as the above requirements are met, but in this study the measures and proportions of grids and ROIs were keep equal as it facilitated the subsequent calculations (since the area unit is the same $\left(/ 3.5 \mathrm{~mm}^{2}\right.$ ), we did not need to recalculate (to $\left./ 1 \mathrm{~mm}^{2}\right)$. The secondary osteons were marked and counted in each ROI. By definition, a secondary osteon was included if the element was in contact with the left or lower edge of the quadrant, but not the right or upper edge [56] (Figure 5). Since there were between 7 and 18 ROls for each cross-section, we calculated median number of secondary osteons per area unit. These variables were then plotted versus chronological age (the median count was used directly without any adjustments for area, as the area of the ROI was always the same $\left.\left(3.5 \mathrm{~mm}^{2}\right)\right)$.

We did find a statistically significant correlation between age at death and secondary osteons, albeit if one outlier was excluded (Figure 6). Such a result is probably to be expected given our small sample size.
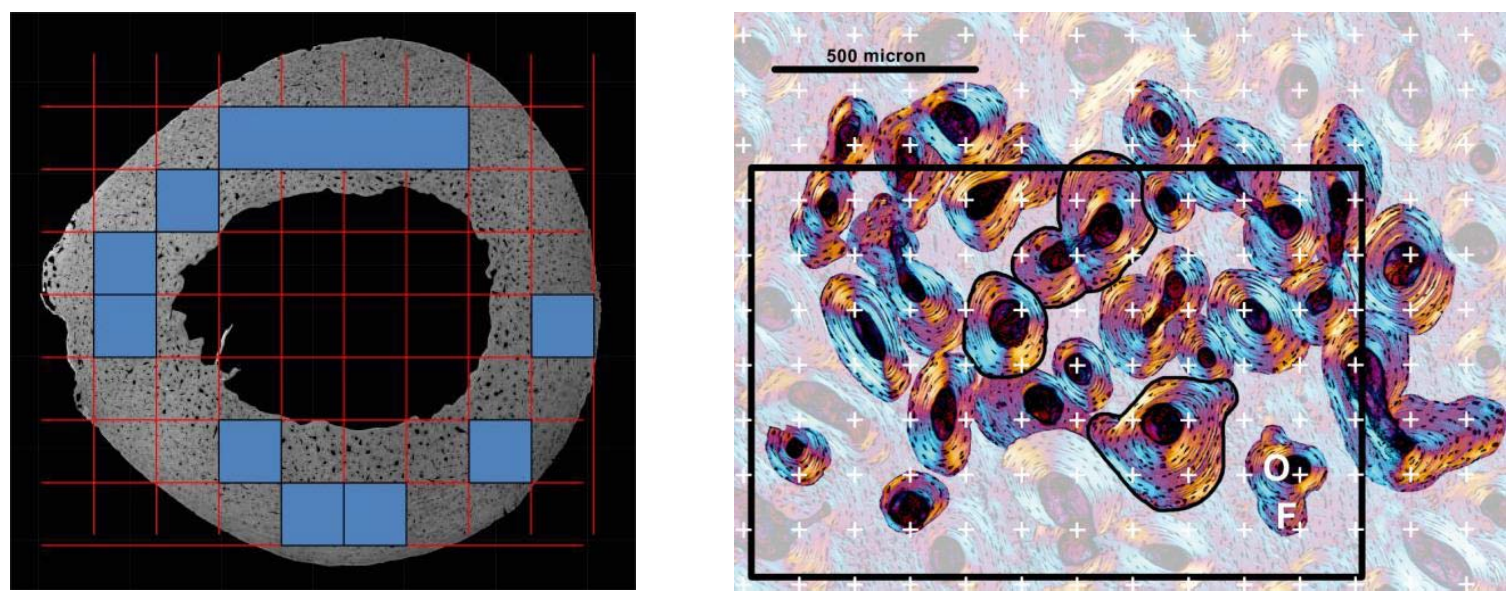

Figure 5. Unbiased stereological selection of cross sectional areas to analyse (left), and how the single structures are defined (right). 
In a subsequent study, we have focused on other structures as well, and specifically on variation between ROls [57]. The areas consisting of all intact secondary osteons plus fragments were outlined and osteon population density, percent osteon population, area and perimeter of the structures were calculated using stereological methods and software. The analyses of intra- and inter-section variability showed no significant difference between the ROIs; i.e. the location within the cross-section of the ROls does not affect the outcome of the analyses.

Overall our results have served to highlight what we think are some rather basic problems of a procedural kind concerning age-at-death evaluation using the microscopical method. Exact definitions of the histological structures and still lacking, and how ROls are selected should also be unequivocal.

\subsubsection{Trabecular bone loss (Paper I)}

Changes in the trabecular bone structures and density in the proximal ends of long bones by X-ray analysis have been correlated successfully with age [58-61]. These methods have been developed on dry bones. There may though be forensic anthropological cases where the removal of soft tissue is not feasible, or where a quick age determination may be useful in the beginning phases of an identification case (e.g., mass graves, mass disasters), without first having to macerate the remains. We therefore investigated whether femoral trabecular bone tissue could be visualised even though the femur was covered by soft tissue. An initial pilot study defined five phases of age-related changes in the trabecular tissue of the proximal end of the femur (Figure 7). A total of $60 \mathrm{X}$-rays, taken from live individuals covering an age span from 14 years to 94 years, were then scored in blind trials. Table 3 shows the median age, and a calculated age range (using the 25 and 75 percentiles) for each defined phase alongside the actual age range. The results demonstrated a clear relationship between age and changes in the trabecular structures: the relationship between the actual ages and the defined phases was highly significant; $\mathrm{H}$ $=39.72, \mathrm{p}<0.00001$ (Figure 8).

The difference between the medians of phases 1 and 2 is 13.8 years, between phases 2 and 3, 17.5 years, between phases 3 and 4, 12.5 years and between phases 4 and 5, 9.0 years. This seems to indicate that the age-related changes in the trabecular bone structure possibly accelerate at the very old age (something also indicated by the studies on the proximal femur and humerus by Acsadi \& Nemeskeri [60]. This merits more studies, and indeed studies, based on CT-scans of bodies brought to our Institute for autopsy, are underway.

\subsubsection{Wrist X-ray (Paper XIII)}

Forensic medical institutions often perform age evaluations of the living at the request of the police [8]. At our Institute, the established procedure in these cases involves: 1) a physical examination; 2) an odontological examination based on evaluation of an orthopantomogram and intraoral dental radiographs; and 3) a carpal X-ray examination, using the Greulich and Pyle Atlas (GPA) method [9]. The application of the GPA is based on a publication from 1959 [62], which comprises a series of X-rays purportedly demonstrating a typical, age-specific standard, progressing from 0 to 18 years of age (females) and to 19 years of age (males).

We performed intra- and inter-observer tests of carpal X-rays in blind trials, and made comparisons between the age-estimations by carpal $\mathrm{X}$-rays and odontological age-estimation. The intra- and inter-observer errors are overall small (not shown). Other studies have found likewise low errors [63-65] did find a higher margin of intra-observer error among untrained observers versus a lower margin among trained radiologists (although not statistically significant). In our study we assessed the error between a radiologist and a non-radiologist (one of the authors) for 159 carpal X-rays in blind trials. We analysed the data following the procedure outlined by [52]. First, a graphical expression of the inter-observer agreement was produced by plotting the data including the "line of equality", i.e., a line on which all points would lie if there was complete agreement between the observations (Figure 9). The agreement was further analysed by plotting the difference against the mean of the two age estimations (Figure 10). In Figure 10 it may thus be seen that in 29 cases where there was disagreement, the difference was one year. In three cases the difference was two years, and in one case three years. Overall, the mean difference was 0.053 years (equivalent to approximately half a month), with a standard deviation of $+/-0.567$ years (approximately equivalent to 7 months). These values are shown in Figure 10 as dotted lines, the so-called limits of agreement [52]. This may be taken to mean that in $95 \%$ (+/- 2 SD) of all the cases, the difference between our age score and the age score of the radiologists is within -1.081 years and +1.187 years.

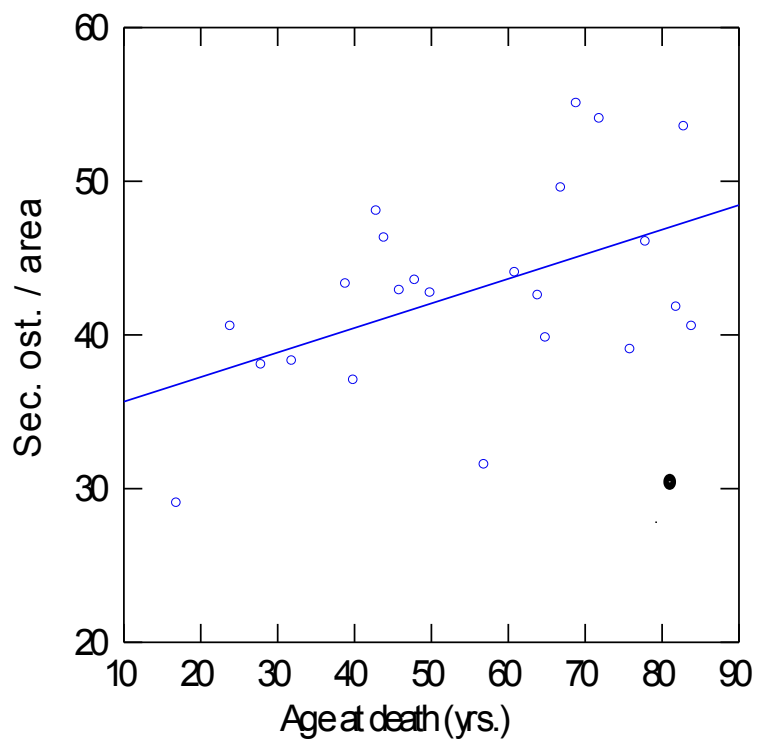

Figure 6. Plot of counts of secondary osteons (medians) per area $\left(3.5 \mathrm{~mm}^{2}\right)$ versus age at death. One data point is designated as an outlier (filled circle). The smoother (linear) was calculated without the outlier.

Table 3. Median age, calculated age range (using the $25^{\text {th }}$ and $75^{\text {th }}$ percentiles) and actual age range for each phase.

\begin{tabular}{|c|c|c|c|c|}
\hline Phase & N & Median Age (yrs.) & Calc. Range (yrs.) & Actual Range (yrs.) \\
\hline 1 & 6 & 22.2 & $20.0-26.8$ & $14-35$ \\
\hline 2 & 9 & 36.0 & $22.5-45.0$ & $18-62$ \\
\hline 3 & 8 & 53.5 & $39.5-57.5$ & $35-58$ \\
\hline 4 & 23 & 66.0 & $56.6-73.6$ & $43-81$ \\
\hline 5 & 14 & 75.0 & $68.5-80.3$ & $61-93$ \\
\hline
\end{tabular}



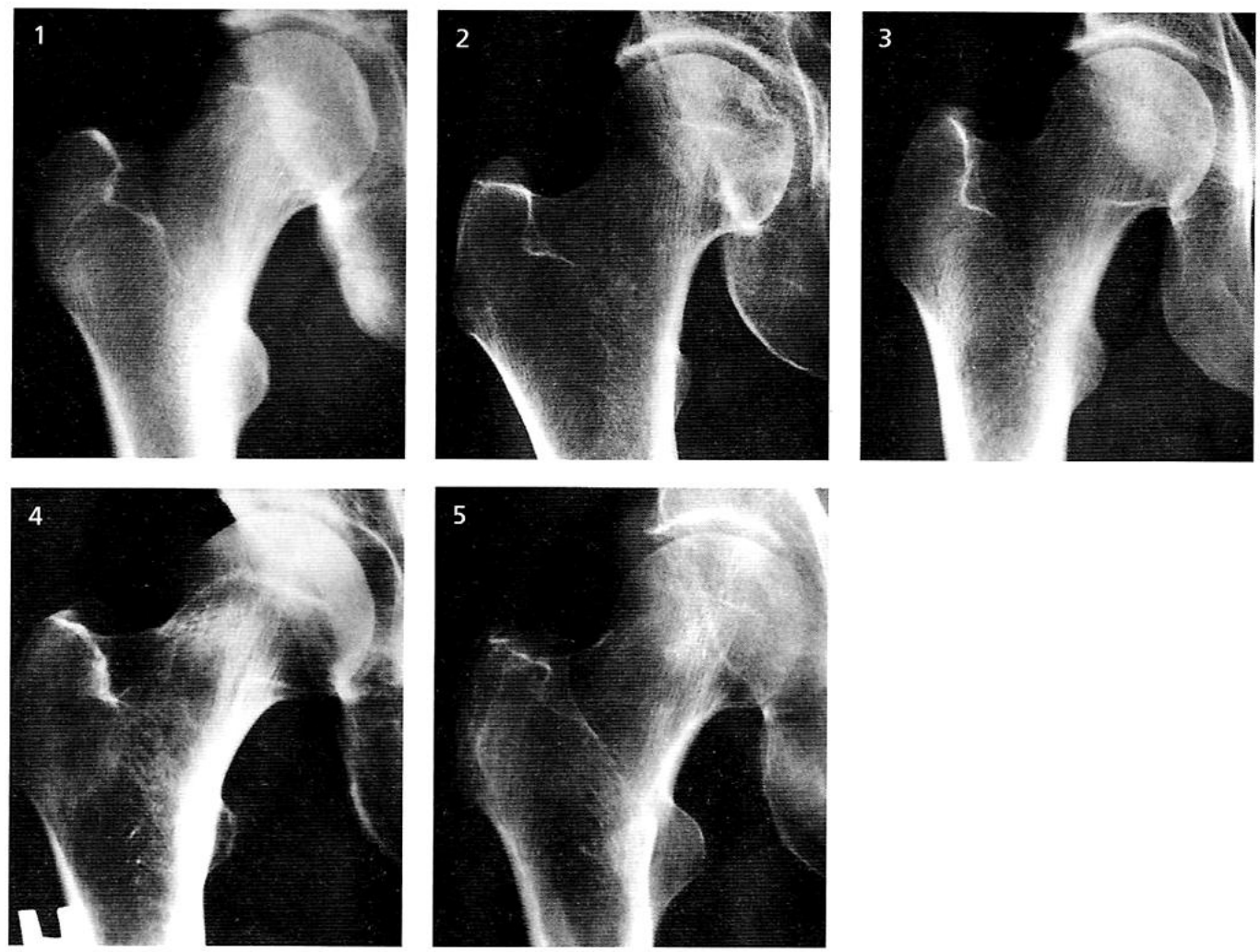

Figure 7. Phases of trabecular loss. Phase 1: Femural head, neck and proximal end of midshaft filled with intact trabecular tissue; Phase 2: Radiolucency of the trabecular tissue beginning distally but not exceeding the lesser trochanter; Phase 3: Radiolucency of the trabecular tissue exceeding the lesser trochanter but not extending into the femural neck, i.e. the radiolucency does not exceed the pertrochanteric line; Phase 4: The radiolucency of the trabecular tissue extends into the femural neck and is observed as a well defined triangular radiolucency between the pertrochanteric line and the femural head; Phase 5: The radiolucency of the trabecular tissue extends into the femural head, most prominantly observed in the proximal area of the femural head

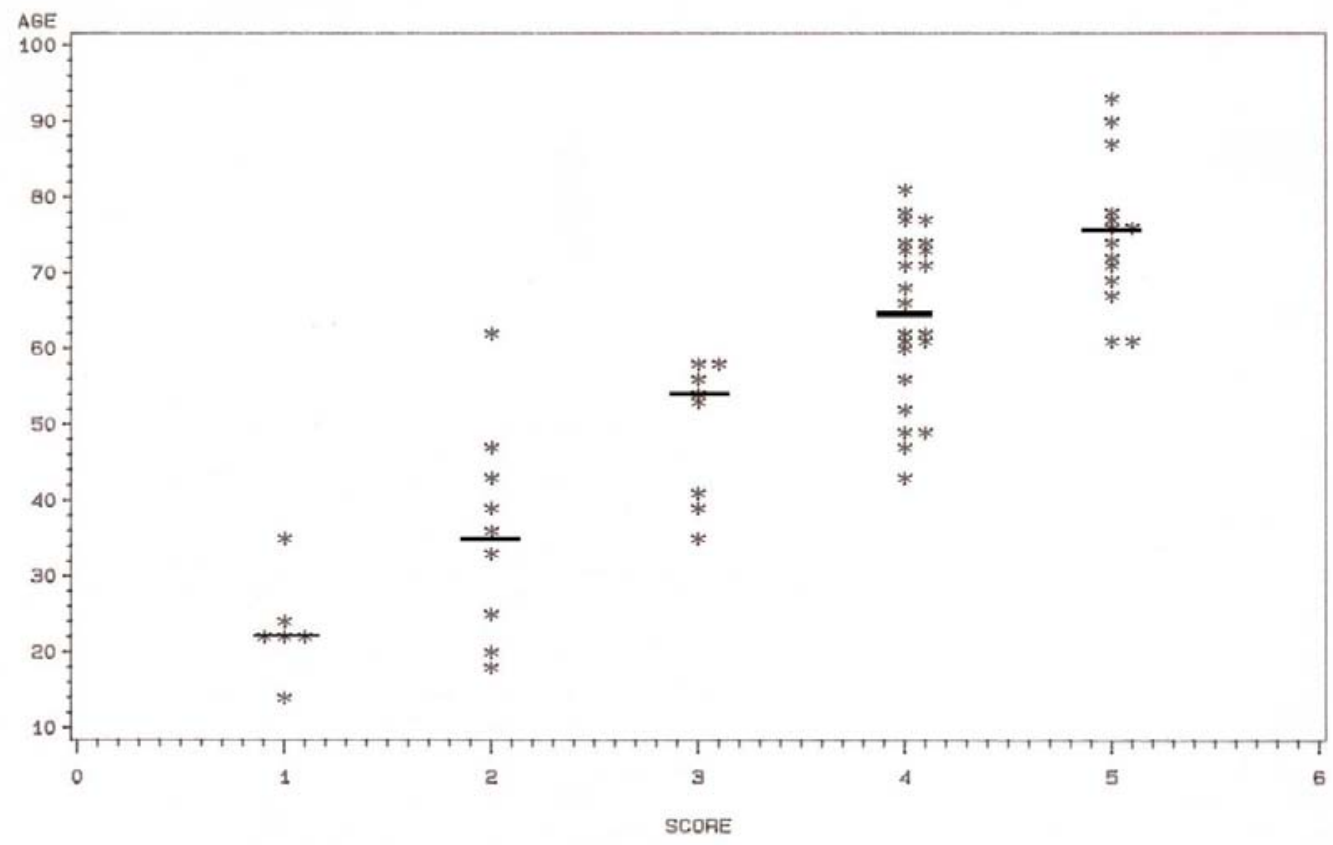

Figure 8. Plot of actual age versus phases (scores). Bar indicates median age of phase. 
Our age estimations, as well as the age estimations by the radiologists by the same method, and the age estimation by the odontologist are shown in Figure 11. There were 17 and 11 cases respectively where the age estimation by the radiologists and by us was outside the age interval determined by the odontologists. However, the radiological estimations are often informally given with a +/- 1 year span. If this were the case for all the radiological age estimations then only 4 age estimations by us and 10 by the radiologists lie outside the interval given by the odontologists ( $9 \%$ and $31 \%$ respectively). All these cases, except one, involve us and the radiologists arriving at an age which is lower than the odontologist, and by far most involve the upper age spectrum, where the odontologist had reached a score of $20-23$ years. Overall, it seems that age estimation by GPA tends to underage the individual as compared to the odontological examination, and this tendency is most pronounced of older juveniles.

We found that our results show that the GPA method is overall easy to use, even by non-experienced users. This is probably also why the method is still widely applied, even though other authors have stated that atlasbased techniques are obsolete [66] and ought to be replaced by other methods, such the Tanner-Whitehouse [67] or the Fels method [68]. The GPA method is also still being incorporated in new CAD-systems (Computer Assisted Diagnostics), such as, e.g., BoneXpert [69]. However, given that there is a difference between the GPA and odontological age assessments, more studies on comparative dental and skeletal aging for geographically different populations would be beneficial, as also mentioned by Schmeling et al. [70]. Finally, specifically as pertains aging of individuals in legal matters, we find that one should closely adhere to the standard deviations given for the GPA method, and intermediary scores should be noted and not just a resultant age. For instance, the final age statement could include a "most likely" age span and a "cannot be excluded" age span. Also, the final age statement should address the problems of reference populations.

Based on this initial study we have since started several research projects aimed at both better describing the error connected with the odontological methods, comparative studies between the GPA, Tanner-Whitehouse and Fels methods, and finally the use of X-rays and MRI scans of the clavicle.

\subsection{Absolute Methods}

All the above mentioned forensic anthropological methods rely on identifying and quantifying certain anatomical features, most often related to non-synovial joint bone surfaces. The precision for these methods is generally around $+/-10$ years. It may be hypothesized that the conventional methods may never really achieve a higher precision, simply because of the nature of quantifying what is a (slow) continuous process of bone remodelling throughout life [e.g., 71].

Developing methods which build upon direct chronology, would in theory by-pass the chronological - biological relationship and the problems herein. Direct methods would rely on more basic biological or nuclear-physical changes, rather than more or less subjective observations of changes in tissues. Also, such methods might be more independent of individual life factors, and thus be theoretically more precise [71].

\subsubsection{Amino acid racemisation (Paper IV)}

Amino-acid racemisation analysis has been presented as a method by which one could bypass the more or less subjective identification of anatomical features, and instead use a chemical process $[72,73]$. The racemisation process is in theory not directly coupled to the ageing of the individual, but simply a process which is dependent on when the proteins were first generated in the body. All amino acids, except glycine, contain a chiral or asymmetric center at the $a$-carbon atom, and the resulting two enantiomers are called the $L$ - and $D$-enantiomer. Proteins are synthesised exclusively from the L-enantiomers. Once a protein is synthesised the L-amino acid residues begin an in situ conversion to the $\mathrm{D}$-enantiomer and this racemization

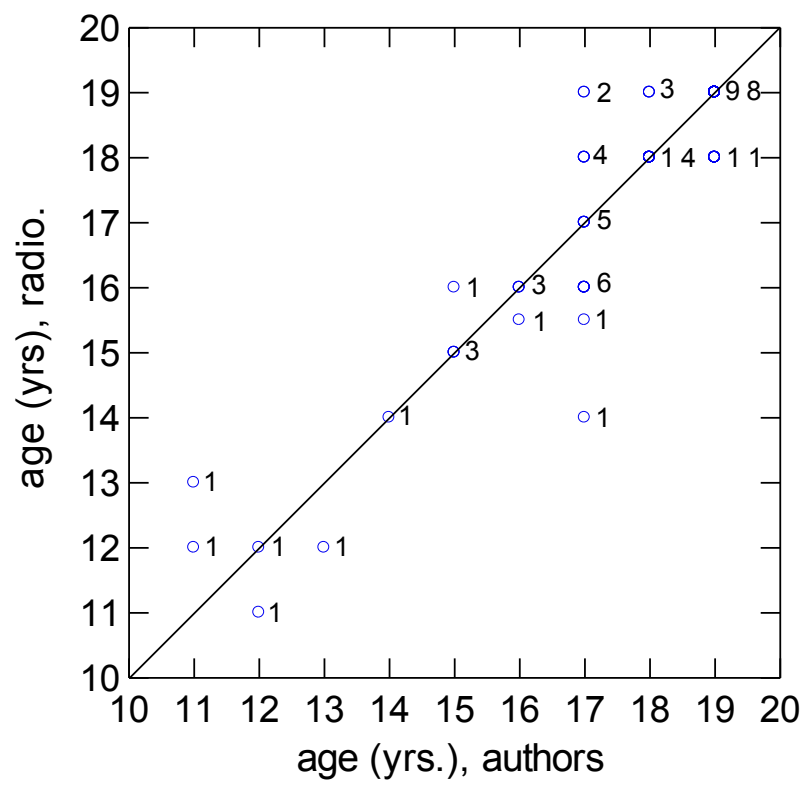

Figure 9. Bland and Altman plot of agreement between the GPA age scores of the radiologists and two of the authors. Numerals indicate number of cases.

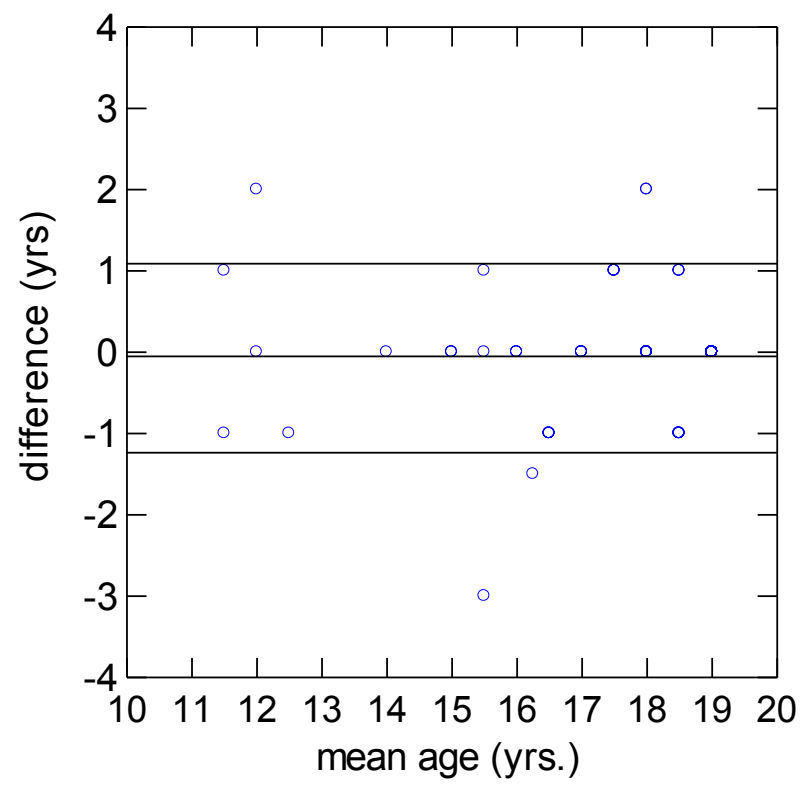

Figure 10. Bland and Altman plot of limits of agreement (see text). 
will eventually first stop when an equilibrium at $50 \%$ of each enantiomer is reached. However, this process is very slow and would take hundreds or thousands of years, depending on the amino acid residue, the sequence, the temperature etc. The progress of the racemization process of a given protein may thus be a measure of the time elapsed since the protein was synthesised, provided that new protein synthesis does not occur and that the protein is metabolically stable. Already in 1975 it was shown that there is a relationship between the chronological age of an individual and the degree of amino acid racemization in collagen from dental tissue [72-74]. Age dependent amino acid racemization has also been observed for proteins found in vertebral discs and eye lens [75-79]. We carried out a study on collagen from dental tissue from a Danish forensic material, and a linear relationship between age and the degree of racemization was observed, the standard deviation of the procedure equaling 5.5 years (Figure 12).

Subsequently, teeth from 6 subjects were analysed in blind trials, and the estimated age deviated from the true age by 1 to 9 years (SD $=4.6$ years) (Table 4). We thus concluded that age estimation using aspartic acid racemization may be an adequate alternative to methods based on clinical assessment of morphological parameters, although our (limited) study does not show a greatly increased improvement in precision over conventional methods.

Strictly speaking, amino acid racemisation is still not a completely absolute method, as it still is a process influenced by temperature (thus being susceptible to different rates if, e.g., a body lies some years in a cold environment like the sea, which will slow down the process) $[80,81]$.

\subsubsection{Radiocarbon dating (Papers XII and XIV)}

Focusing on processes on the atomic level would circumvent the above problem. Such non-biological markers could be the rate of decay of radioactive isotopes, which is not affected by biological processes. Such a non-biological marker, however, needs to fulfil three basic criteria: it has to be incorporated in biological tissues at a specific point in time, e.g. around birth, and it has to be isolated in the organism, so that it is not in continuous equilibrium with extra-organismal concentrations. Thirdly, one has to be able to calibrate the marker versus chronologically known events.

We have published a method whereby the year of birth may be calculated to within +/- 1.5 years by analysing the ${ }^{14} \mathrm{C}$ content of the eye lens, following a seminal study by Spalding et al. [82] using dental enamel. The method is based on the fact that all living tissues undergo a continuous turnover, substitution and remodelling [e.g. 83], both on

Table 4. Determination of the age of 6 subjects from measurements of the degree of aspartic acid racemization in collagen from first permanent molar teeth. D/L-Asp, ratio between the $D$ - and L-enantiomers of aspartic acid. Age is in years.

\begin{tabular}{|c|c|c|c|c|}
\hline Sample: & D/L-Asp & Estimated age & Actual age & Deviation \\
\hline Unknown \#1 & 0,04562 & 67 & 59 & 8 \\
\hline Unknown \#2 & 0,03523 & 29 & 24 & 5 \\
\hline Unknown \#3 & 0,03498 & 28 & 26 & 2 \\
\hline Unknown \#4 & 0,03427 & 26 & 25 & 1 \\
\hline Unknown \#5 & 0,03451 & 27 & 36 & -9 \\
\hline Unknown \#6 & 0,03588 & 32 & 33 & -1 \\
\hline
\end{tabular}

the cytological and tissue level, except for dental enamel [82], neurons in the brain [84], and the special proteins in the eye lens fibres, termed crystallines. The lens fibre cells in the nucleus of an adult lens are thought to be produced during early embryonic life [85]. The human lens grows rapidly in the embryo and during the first postnatal year [85]. Because the epithelial basement membrane (lens capsule) completely encloses

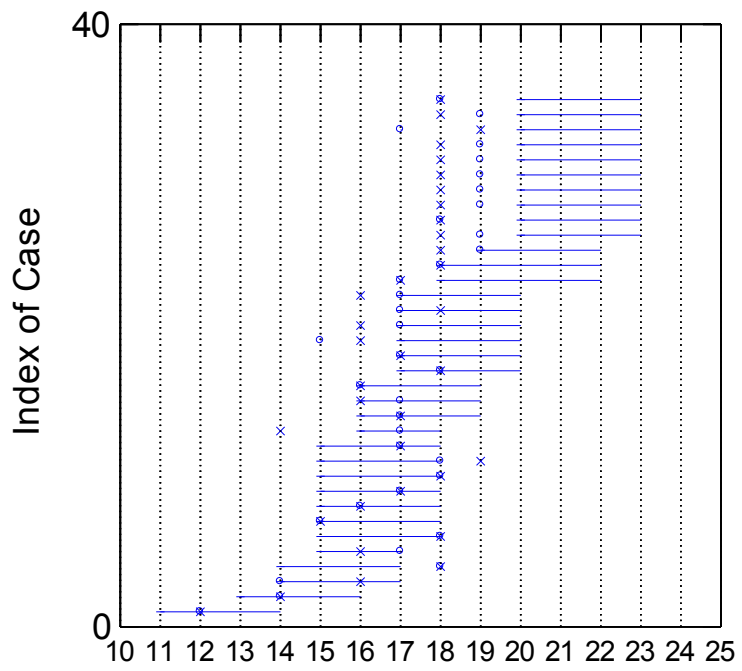

Figure 11. Agreement between odontological and GPA age estimation. Horizontal lines indicate the age span given by the odontologist; $\mathrm{X}=$ age estimate by two of the authors; $\mathrm{O}=$ age estimate by radiologists.

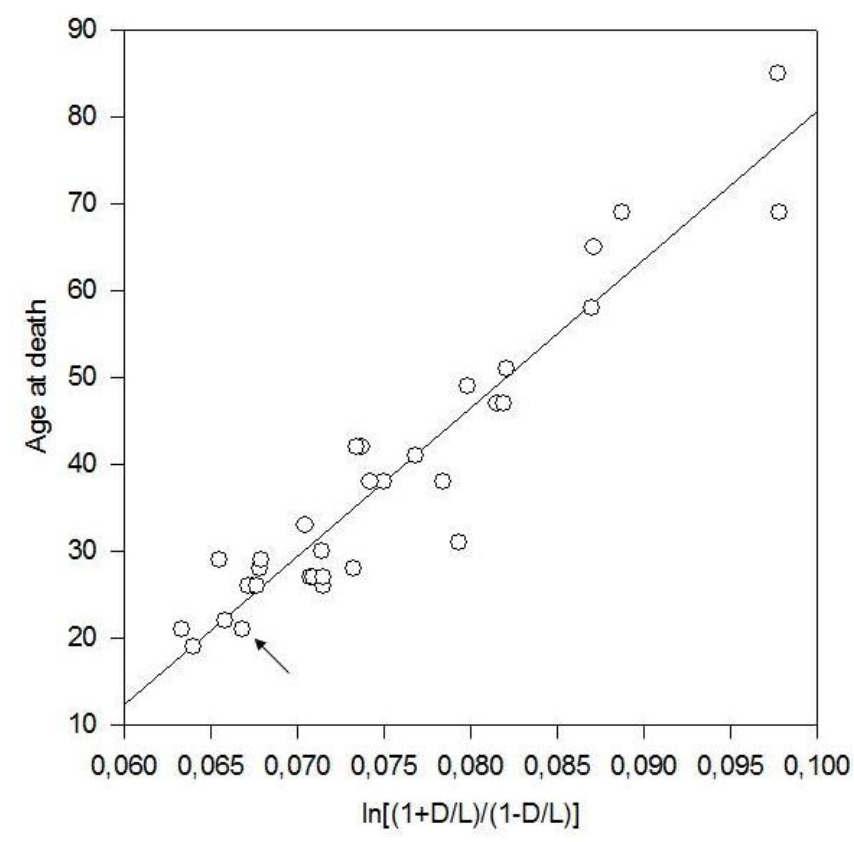

Figure 12. Age at death in relation to the degree of aspartic acid racemization in collagen from first permanent molar teeth from 32 subjects. D/L-Asp, ratio between $\mathrm{D}$-aspartic acid and L-aspartic acid. The arrow indicates a second permanent molar from a 27 years old subject; the data point is plotted at $27-6=21$ years to simulate the true age of the tooth, and shows that this corrected data point did not deviate from the results obtained using the first molars. 
the lens, desquamation of aging cells is impossible, and due to the complete absence of blood vessels or transport of metabolites in this area, there is no subsequent remodelling of these fibres or removal of degraded lens fibres.

The method exploits the radical variations of the atmospheric ${ }^{14} \mathrm{C}$ content during the last 50 years to date the formation of the lens crystallines. The concentration of ${ }^{14} \mathrm{C}$ in living tissues reflects the atmospheric ${ }^{14} \mathrm{C}$ content at the time of growth. This is because cosmogenic ${ }^{14} \mathrm{C}$ in the atmosphere reacts with oxygen to form carbon dioxide $\left(\mathrm{CO}_{2}\right)$, which is incorporated by plants, and then ingested by animals. The plants and animals are ultimately ingested by humans. If there is only minimal turnover in the eye lens, the content of ${ }^{14} \mathrm{C}$ in the lens crystallines should thus reflect the atmospheric concentration at the time the lens crystallines were formed. The amount of ${ }^{14} \mathrm{C}$ in the atmosphere (see Figure 13) was almost constant until about 1955, when nuclear-bomb tests caused it to rise dramatically [86]. Subsequent to the Test Ban Treaty in 1963 the concentration has decreased rapidly, mainly because the atmospheric ${ }^{14} \mathrm{C}$ has diffused into the oceans, while radioactive decay (the half-life of ${ }^{14} \mathrm{C}$ is 5730 years) is of minor importance [87]. Since the change in concentration is significant even on a yearly basis this allows very accurate dating [88,89], see Figure 14 .

Indeed, we were able to ascertain the year of birth of three dead babies found in a deep-freezer to within 1-2 years (1986, 1988 and 2004, respectively), using the method. In spite of this evident success of the method there was one aspect of the data that represents a puzzle. The ${ }^{14} \mathrm{C}$ levels of the lenses were consistently smaller than those of the nails, corresponding to apparent later formation of the lenses (Figure 15). In fact the idea of combining (averaging) the ${ }^{14} \mathrm{C}$ data of nails and lenses is not supported by the data, i.e. the hypotheses that the nails and lenses are formed at the same time is less than $5 \%$ probable. Evidently, for a newborn baby the physical formation times cannot possibly differ by more than 9 months, during which the mother could however have changed her dietary preferences in terms of terrestrial/marine/petrochemical proportions leading to ${ }^{14} \mathrm{C}$ and apparent ages differences, not related to the real time difference. A central issue is where the baby gets the carbon from - the mother or the food? Different amino-acid composition may be part of the explanation too. The two proteins, the crystallines of the eye lenses and the keratin of the nails, are likely to contain distinct proportions of different amino acids. Furthermore in the case of a mixed diet (terrestrial + marine + petrochemical) the different amino acids are likely to have different ${ }^{14} \mathrm{C}$ content. See also [90].

In order determine get a better understanding of the nail-lens difference in the ${ }^{14} \mathrm{C}$ level we propose analysis of addition lens-nail pairs to see whether the observed trend is typical or something particular for the mother discussed here. As a second step, separation of the proteins into the individual amino acids prior to the ${ }^{14} \mathrm{C}$ measurements is feasible [91] and likely to reveal more about the underlying mechanism. The precision of the radiocarbon method relies on the rate of change of the atmospheric ${ }^{14} \mathrm{C}$. This changed dramatically due to the nuclear bombs as illustrated by the bomb pulse. Obviously, with the present flattening out of the curve, precision will suffer, as was indeed the case here: we were able to calculate the birth year with a higher precision for babies \#2-3, than for baby \#1. As such, this could point to a declining usefulness of the method, at least as far as forensic cases with individuals borne inside the last few years are concerned. The method will continue to be precise for individuals born in the period between these last few years and the beginning of the bomb pulse (individuals now between infant age and in their mid-50s).

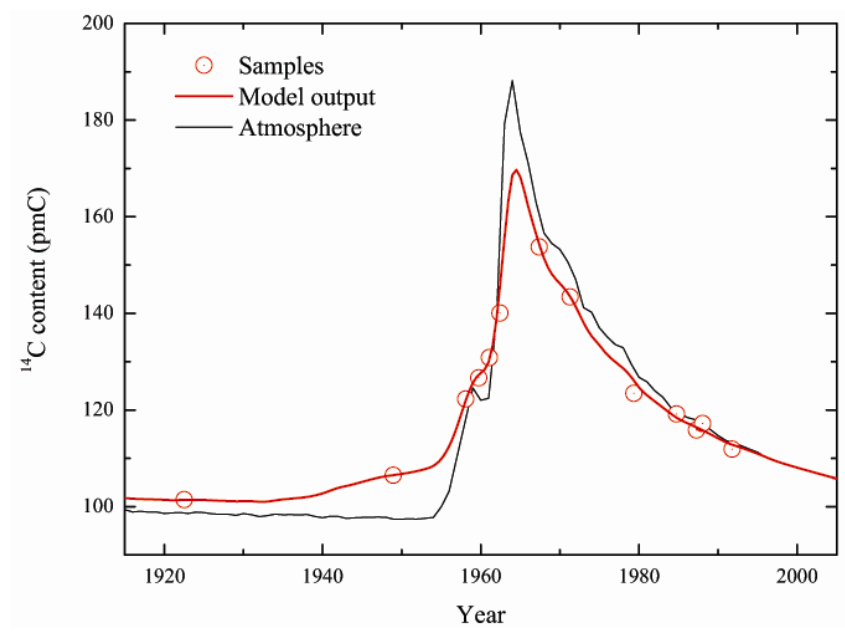

Figure 13. Nuclear bomb tests during 1955-63 produced large amounts of $14 C$, which after this period has declined exponentially (thin, grey line). Comparing the amount of $14 \mathrm{C}$ in eye-lens crystallines (red circles, plotted as a function of the year of birth) with the atmospheric concentration in units of pmC (percent modern Carbon) has made it possible to investigate the timing of the formation process. The red curve shows the output from our resulting lens-formation model, which provides the basis for predicting the year of birth accurately.

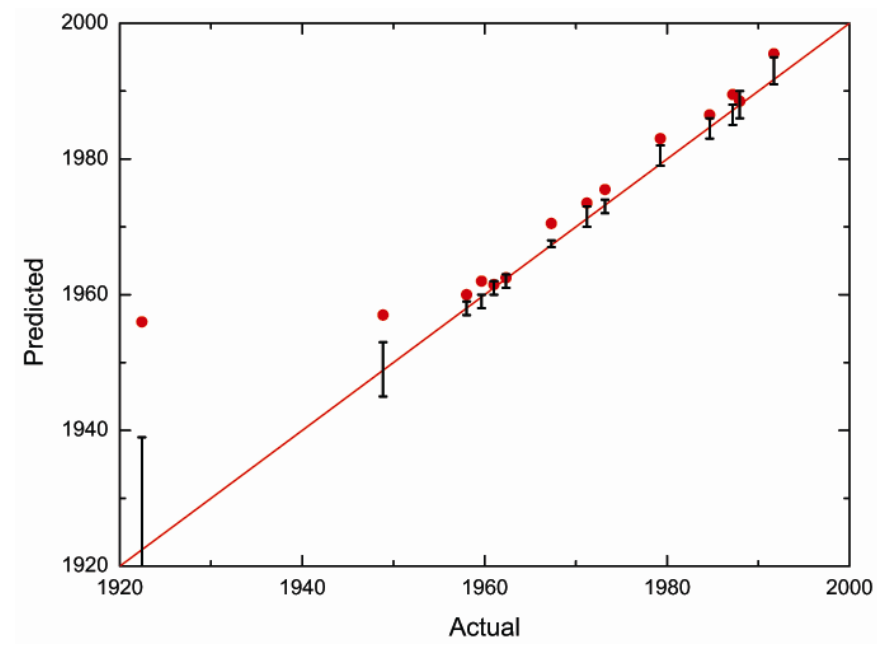

Figure 14. The year of birth of a person may be predicted from the $14 \mathrm{C}$ content of the eye-lens crystallines. In an over-simplistic picture the eye lens crystallines are formed at the birth year of the individual. The year of birth predicted in that way (red circles, showing only the centre value of the $95 \%$ confidence interval) is close to the actual year but evidently different, in particular for the oldest individuals. More accurate results are obtained by using our model, because it takes into account that the crystallines grow later in life too: The resulting predictions (black vertical bars, showing the $95 \%$ confidence interval) are in agreement with the actual values in all cases. The two ways of predicting the year of birth correspond to using the black (atmospheric) or the red (eye-lens model) curve in Figure 13, respectively. The red line shows the ideal 1:1 ratio between the predicted and actual year of birth. 

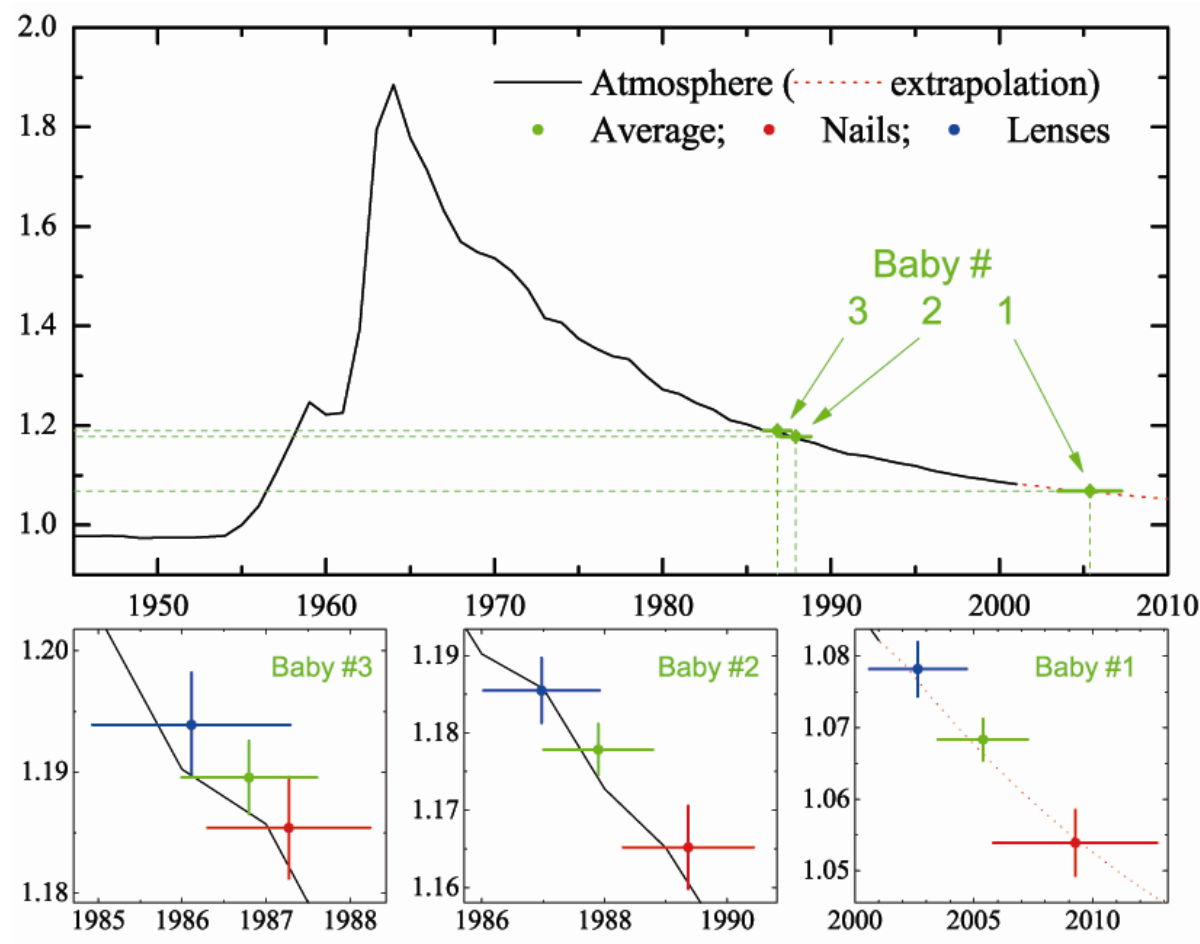

Figure 15. The ${ }^{14} \mathrm{C}$ level of the atmosphere and the babies. Within the last 50 years accurate dating is feasible by tracing the ${ }^{14} \mathrm{C}$ level of human tissues back to its atmospheric origin (solid curve). The dashed lines indicate how the measured ${ }^{14} \mathrm{C}$ levels are interpolated horizontally from the vertical axis onto the plot of the atmospheric ${ }^{14} \mathrm{C}$ concentration and subsequently down onto the horizontal axis. In this manner the measured ${ }^{14} \mathrm{C}$ raw data are transformed into calendar dates. The graphs display the ${ }^{14} \mathrm{C}$ concentration in the form of 'fraction modern carbon', $\mathrm{F}\left({ }^{14} \mathrm{C}\right)$,(vertical axes), as a function of the time (in years, horizontal axes); the atmospheric data of Kueppers et al. [2004] has been extended by an exponential fit (rightmost dotted curve). The average ${ }^{14} \mathrm{C}$-levels and corresponding dates ('combined value') of the three babies discussed in the text are shown as the middle crosses in the three bottom graphs. In addition, the separate values of nails (lower crosses) and lenses (upper crosses) are displayed in the three bottom graphs. The vertical and horizontal lines indicate $68.2 \%$ probability intervals (1 s) of the ${ }^{14} \mathrm{C}$ raw data and $95.4 \%$ probability intervals of the calendar dates, respectively. The substantial variation of the atmospheric ${ }^{14} \mathrm{C}$ concentration is due to tests of nuclear weapons around the middle of the previous century and subsequent absorption of the excess ${ }^{14} \mathrm{C}$ into the oceans.

\section{SEX EVALUATION}

Evaluation of the sex of a skeleton rests on identifying sex-characteristic and sex-specific morphological traits [e.g., 5,6,12]. At its most basic, the sex is determined by the sex-chromosomes of the individual (the genetic sex), which again results in male or female gonads (gonadal sex), and again in male or female sex organs (genital sex). These traits constitute the primary sex sex characteristics. However, none of these traits can be identified in skeletal remains (except, of course, by DNA-testing). This leaves the secondary sex characteristics. Male testosterone levels will thus increase muscle mass and skeletal mass, enhancing size, weight and muscle attachments for males in confront to females. All else being equal, an average male skeleton will be bigger, the bones bigger in all dimensions, heavier, and with more pronounced muscle attachments, e.g. the linea aspera, basal occipital part of the skull, etc. However, there will be a zone of overlap, making sex determination based on these secondary characteristics not always accurate. The pelvis stands out as the bone structure with the most marked sexual dimorphism: the female pelvis is proportionally wider and more flat, whereas the male pelvis is proportionally higher and more narrow [92]. The general secondary characteristics still apply (the male pelvic bones being bigger, heavier and with more pronounced muscle attachments). This makes the pelvis, and the single bones of the pelvis, the most reliable bones for identifying the sex of a skeleton. The sex specific traits are, amongst others, the sharpness of the subpubic angle and the ischiadic angle, the shape of the foramen obturatorium and the symphyseal and auricular faces, and the profile of the sacrum [e.g., 5,6,12].

As with age evaluation, the forensic anthropological diagnosis of sex is most often performed by comparing morphology of certain skeletal structures to standards [Buikstra and Ubelaker, 1994], including using a staging from very male over unknown sex to very female. Furthermore, anthropometric formulae have been developed for almost every bone and identifiable bone structure $[6,93]$. A much used example would be the diameter of the femoral head: if this measures more than $47.5 \mathrm{~mm}$ the bone is probably of a male; less than $42.5 \mathrm{~mm}$ probably of a female [93].

As with the chapter on age evaluation, the following will present how several sex evaluation techniques have been developed, tested and examined.

\subsection{Skull thickness (Papers V and VIII)}

Several studies have shown conflicting results concerning the relationship between cranial thickness and sex, age and general body build [94-102]. 
This could be a result of having used collection specimens where medical records are not available or only very scant (e.g. only the direct cause of death is recorded), thus not allowing observers to control for diseases which may influence bone metabolism and structure. Another possible cause for inconclusive results may be the wide variety of sampling methods and sample points [94-102]. Sampling methods also include cranial thickness as measured on cranial X-rays [103-107] or by other indirect means [98]. While the external cranial surface is overall fairly smooth, at least above linea nuchae and temporal-masseter line, the internal surface is much more irregular. This will of course have implications for measurements, both taken directly with calipers on cut margins or on trephined specimens or when measuring thickness on cranial X-rays. We have added to these studies, using a modern forensic material with complete autopsy results and antemortem medical information. We further wanted to analyse whether trends useful for sexing and ageing might emerge if we focused on the diploe (the cancellous or spongy bone within the laminae, or tables, of the vault bones of the skull). A few other studies have addressed the diploeic thickness, but these studies have mainly dealt with issues of cranial reconstructive surgery $[108,109]$.

The cranial vault bone biopsies were taken from four sites on each individual: 1) $1 \mathrm{~cm}$ in front of the bregma; 2) $1 \mathrm{~cm}$ behind lambda ; 3) left euryon and 4) right euryon. The thickness of each specimen was measured without knowledge of sex or age using a digital caliper connected to a computer [110]. We used X-rays to visualise the bone components, in order to measure the diploeic thickness (Figure 16).

Males and females did not differ significantly in cranial thickness, except for right euryon were there was a statistically significant difference with females having the thickest measures. Regarding diploiec thickness, we found no statistically significant differences between males and females for the diploeic thickness, except for the frontal biopsies where there was a statistically significant difference with males having the thickest measures (Tables 5-8, and Figure 17).
In our studies there were no statistically significant correlation between age and cranial nor diploeic thickness, thus reflecting results of Schmitt and Saternus [97], Ishida \& Dodo [101] and Ross et al. [102]. The diploeic bone thickness co-varies with the total thickness. The LOWESS plots generally seem to indicate more variation with age for females than males as regards frontal and occipital thickness, whereas there may be a slight trend for females to have reduced thickness past 50-60 years of age, whereas males diverge to slightly thicker skulls. Several authors have recorded a slight increase in cranial thickness with age and have related the frontal bone thickness increase to hyperostosis frontalis interna $[96,97,102,111,112]$, while other results, also showing age-related increase in thickness [105], were later ascribed to inconsistencies in the radiologic examination [106].

Also, cranial thickness cannot be inferred from an individuals' general build and stature. Powerfully built individuals may in fact have rather thin cranial vaults, whereas small, slightly built people may have thick skulls. Since the degree of cranial fracturing due to external force has been related to cranial thickness, see e.g., Gurdjian et al., [113], this may have implications in a forensic pathological setting, when the forensic pathologist is called upon to ascertain the degree of force used in cases with interpersonal violence with resulting severe or fatal trauma to the cranium $[114,115]$.

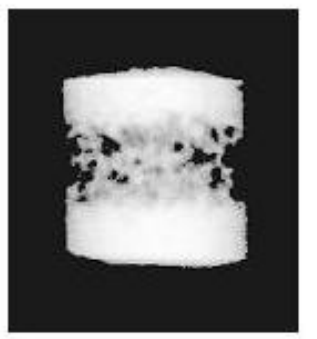

External table (compact bone)

Diploe (trabecular or spongy bone)

Internal tablr (compact bone)

Figure 16. Digital radiograph showing the diploe.

Table 5. Pearson correlation matrix for cranial thickness for males. Probabilities are Bonferroni adjusted probabilities (Bartlett Chi-square statistic: 42.423, $\mathrm{DF}=6 ;$ prob. $=0.000)$

\begin{tabular}{|c|c|c|c|c|c|c|c|c|}
\hline & \multicolumn{3}{|c|}{ Frontal } & \multicolumn{2}{c|}{ Occipital } & \multicolumn{2}{c|}{ Right euryon } & \multicolumn{1}{c|}{ Left euryon } \\
& corr. coef. & $p$ & corr. coef. & & & & \\
\hline Frontal & 1.000 & 0.0 & & & & & \\
\hline Occipital & 0.439 & 0.019 & 1.000 & 0.0 & & & \\
\hline Right eu & 0.358 & 0.110 & 0.128 & 1.000 & 1.000 & 0.0 & \\
\hline Left eu & 0.414 & 0.035 & 0.229 & 0.833 & 0.687 & 0.000 & 1.000 & 0.0 \\
\hline
\end{tabular}

Table 6. Pearson correlation matrix for cranial thickness for females. Probabilities are Bonferroni adjusted probabilities (Bartlett Chi-square statistic: 19.829; $\mathrm{DF}=6 ;$ prob $=0.003$

\begin{tabular}{|c|c|c|c|c|c|c|c|c|}
\hline & \multicolumn{2}{|c|}{ Frontal } & \multicolumn{2}{|c|}{ Occipital } & \multicolumn{2}{|c|}{ Right euryon } & \multicolumn{2}{|c|}{ Left euryon } \\
\hline & corr. coef. & $p$ & corr. coef. & $p$ & corr. coef. & $p$ & corr. coef. & $p$ \\
\hline Frontal & 1.000 & 0.0 & & & & & & \\
\hline Occipital & 0.560 & 0.049 & 1.000 & 0.0 & & & & \\
\hline Right eu & 0.121 & 1.000 & 0.429 & 0.313 & 1.000 & 0.0 & & \\
\hline Left eu & 0.212 & 1.000 & 0.303 & 1.000 & 0.613 & 0.019 & 1.000 & 0.0 \\
\hline
\end{tabular}


Table 7. Pearson correlation matrix for diploeic thickness for males. Probabilities are Bonferroni adjusted probabilities.

\begin{tabular}{|c|c|c|c|c|c|c|c|c|}
\hline & \multicolumn{2}{|c|}{ Frontal } & \multicolumn{2}{|c|}{ Occipital } & \multicolumn{2}{|c|}{ Right euryon } & \multicolumn{2}{|c|}{ Left euryon } \\
\hline & corr. coef. & $p$ & corr. coef. & $p$ & corr. coef. & $p$ & corr. coef. & $p$ \\
\hline Frontal & 1.000 & 0.0 & & & & & & \\
\hline Occipital & 0.473 & 0.028 & 1.000 & 0.0 & & & & \\
\hline Right eu & 0.312 & 0.433 & 0.138 & 1.000 & 1.000 & 0.0 & & \\
\hline Left eu & 0.324 & 0.370 & 0.177 & 1.000 & 0.712 & 0.000 & 1.000 & 0.0 \\
\hline
\end{tabular}

Table 8. Pearson correlation matrix for diploeic thickness for females. Probabilities are Bonferroni adjusted probabilities.

\begin{tabular}{|c|c|c|c|c|c|c|c|c|}
\hline & \multicolumn{2}{|c|}{ Frontal } & \multicolumn{2}{|c|}{ Occipital } & \multicolumn{2}{|c|}{ Right euryon } & \multicolumn{2}{|c|}{ Left euryon } \\
\hline & corr. coef. & $p$ & corr. coef. & $p$ & corr. coef. & $p$ & corr. coef. & $p$ \\
\hline Frontal & 1.000 & 0.0 & & & & & & \\
\hline Occipital & 0.352 & 1.000 & 1.000 & 0.0 & & & & \\
\hline Right eu & 0.336 & 1.000 & 0.137 & 1.000 & 1.000 & 0.0 & & \\
\hline Left eu & -0.113 & 1.000 & -0.017 & 1.000 & 0.628 & 0.055 & 1.000 & 0.0 \\
\hline
\end{tabular}
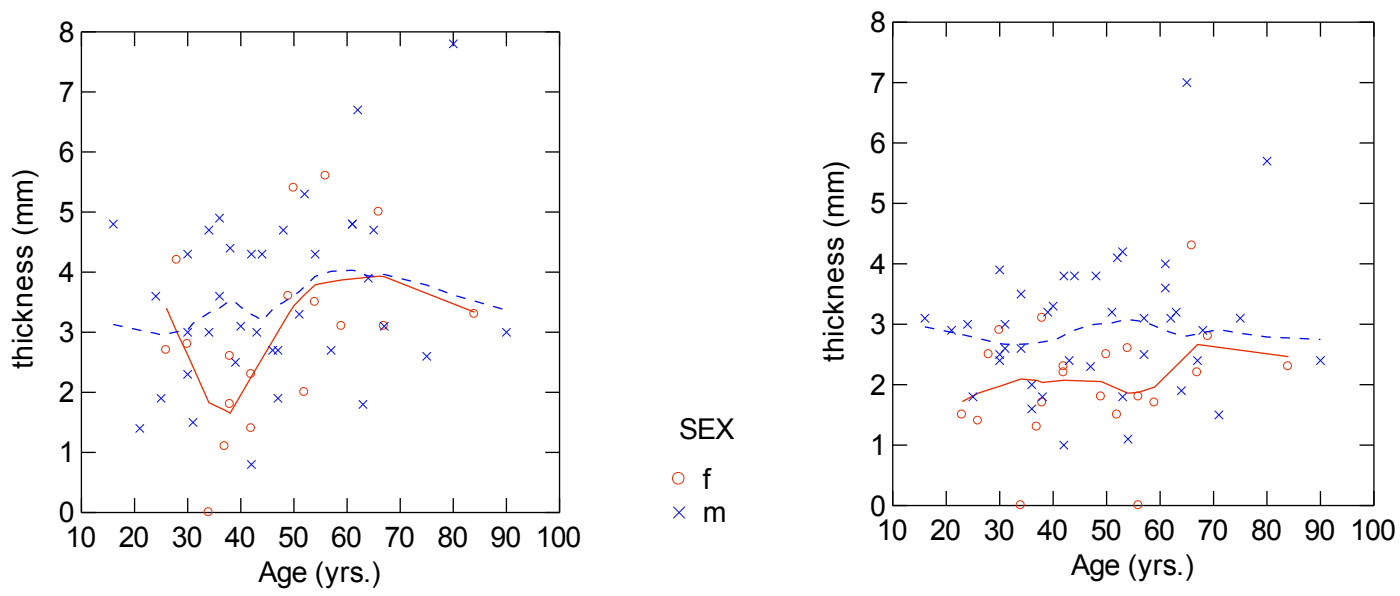

SEX
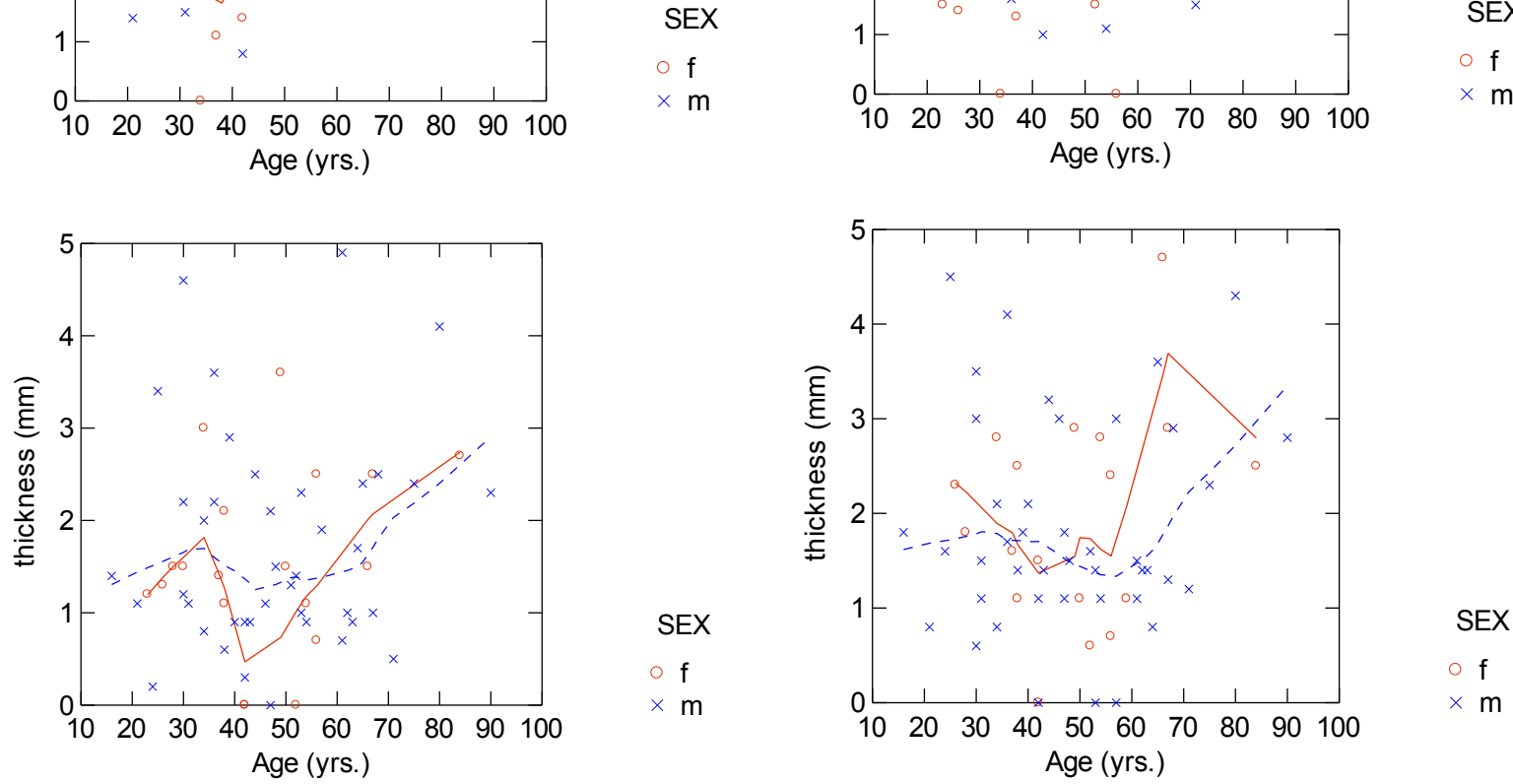

Figure 17. Scatter plots showing cranial thickness against age for frontal (o) and occipital (x) sampling points with LOWESS smoothing (unbroken line: frontal values; broken line: occipital values). Upper graph: females, lower graph: males. 


\subsection{Lateral angle (Paper VII)}

A morphological sexing method is reliant on certain anatomical structures to be present and reasonably well preserved. Bone density and distribution of trabecular and cortical components are among the important factors involved in preservation of skeletal elements [116,117]. In terms of preservation the petrous part (or petrous bone) of the temporal bone is one of the most dense and robust structures of the human skeleton. It is our experience that the petrous bones may be easily identifiable in cremated human remains, e.g. from the Scandinavian and Northern European Bronze Age and Iron Age, see e.g., Wahl [118].

We have therefore evaluated the so-called lateral angle method of the internal acoustic meatus as a way to estimate the sex of an individual. The method was primarily developed by Wahl in 1981, but little has been written internationally on this method [119]. The method is based upon the medial opening of the internal acoustic canal in the petrous bone of the skull (Figure 18). The internal acoustic canal carries the vestibulocochlear and facial nerve. The most proximal part of the canal, and thereby the meatus or opening, was reported by Wahl [120] to exhibit sexual dimorphism in the angle at which the canal opens up to the surface of the petrous bone. Wahl quantified this angle by filling up the proximal part of the canal with clay, and measuring the angle displayed by the cast in relation to the bone surrounding the opening (Figure 19). Wahl defined this angle as the lateral angle. An angle above or below $45^{\circ}$ was indicative of sex: females had angles of $45^{\circ}$ or more, and males angles below $45^{\circ}[119,121]$.

Our study found that this sectioning point is statistically significant and does result in the best discrimination. We had access to a forensic sample comprising 113 unilateral petrous bones and 60 pairs of petrous bones (the bilateral sample). The overall agreement was $83.2 \%$ for the unilateral sample, and $81.67 \%$ for the bilateral sample. The Cohen kappa statistics, which correct for chance agreement, were also clearly indicative of good agreement. It was not found that a higher accuracy was achieved by having pairs of petrous bones. The relationship between left and right side was very tight, and although there were differences in angle sizes, this did not influence the sex determination. Overall, the method assigned $83.2 \%$ of the petrous bones to the correct sex (Figure 20). While not an accuracy comparable to other standard physical anthropological methods, e.g. such as hip morphology [12], it does reflect statistically significant dimorphism. To further evaluate this, the lateral angle method was therefore directly compared to conventional anthropological methods. For these tests a combined archaeological material was used, consisting of reasonably complete skeletons where sex determination was made by assessing pelvic morphology as well as cranial morphology. It is important to point out that the pelvic and cranial sex determinations were carried out independently. Obviously, the true sex is not known for the archaeological sample, but we did find good overall agreement, especially as pertains to the pelvic sex (86.67\%). The latter was most marked for females. While agreement between the lateral angle and the cranial and pelvic sex respectively, was the same for males, pelvic sex showed a much better agreement with the lateral angle than did cranial sex for females, respectively. Assuming, as is generally acknowledged, that pelvic morphology is more "correct" this may indicate that the lateral angle size perhaps is not just related to cranial size, but may also reflect differences in cranial (base) form. In this respect we find it interesting that the lateral angle size showed the best concordance with sex determined from pelvic morphology rather than cranial morphology.

Future studies will focus on cranial morphology and craniometry to further develop this inquiry. These studies will also include research into infant cranial base and brain stem development. In the present study, four petrous bones from the forensic sample as they were from sub-adults (actual ages were 7, 9, 14 and 17 years). However, the lateral angle size was measured and in three of four cases made a correct sex determination (all the petrous bones were from males and were determined as such except

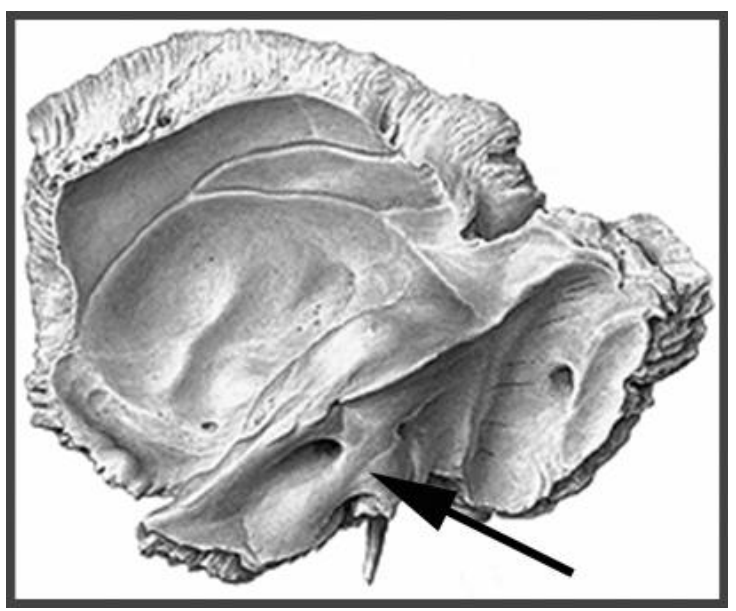

Figure 18. Medial view of the right temporal bone. The petrous part or bone is the lower half of the bone. An arrow points to the opening of the internal acoustic canal (modified from Sobotta and Becher [1975]).
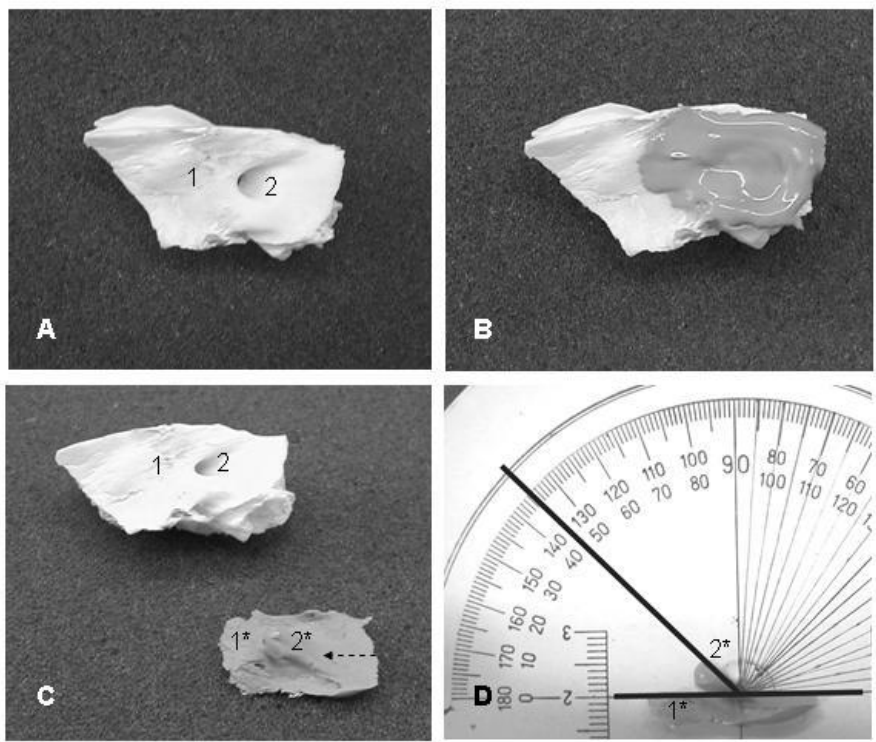

Figure 19. A: Isolated petrous part of a left temporal. B: Cast material has been introduced into the internal acoustic canal and the area surrounding the opening. C: The cast after setting and removal. D: The cast has been bisected, and the flat cut surface is laid against a protractor, and the lateral angle is read off $\left(45^{\circ}\right) .1$ : facies posterior of the petrous bone; 2 : the lateral wall of the internal acoustic meatus; $1^{*}$ and $2^{*}$ : same structures on cast. Arrow in $2 \mathrm{C}$ indicates where the cast is bisected. 
for the 14-year old male, where the lateral angle was measured to $45^{\circ}$ and hence designated as female). As noted in the introduction, this may show the potential utility of this method for sexing sub-adults.

\subsection{Diameter of the meatus acousticus (Paper $\mathrm{X}$ )}

The lateral angle method relies on making casts. As such, this makes it somewhat more difficult to use. Since using the petrous bone may be advantageous, we wanted to investigate whether a simpler parameter might still carry some information. We hence tested the diameter of the internal opening of the acoustic canal in the petrous part of the temporal bone for sex determination of skeletal remains. The method involves measuring the diameter using a suite of ordinary drills. Using the above forensic sample of 113 left petrous bones with known sex, we found a statistically significant difference in diameter between males and females (Figure 21). However, the low predictive value $(70 \%)$ for correct sexing using two sectioning points $(<3.0 \mathrm{~mm}=$ female; $>3.5 \mathrm{~mm}=$ male) was disappointing. No additional accuracy was gained by employing both left and right petrous bones (a bilateral sample of 60 petrous bones was also tested); left and right side diameter are highly correlated. Intra- and inter-observer testing showed that the same diameter was measured in $19 / 20(=95 \%)$ of the cases. This was also the case for the inter-observer variation analysis, where the same diameter was measured in $19 / 20(=95 \%)$ of the cases. The cases with different diameter differed by only by $0.5 \mathrm{~mm}$ (one "drill"-step).

We expect to continue work on devising methods for sex evaluation based on traits of the petrous bone. This is because of the early cessation of bone growth and development. Schmid \& Dahm [122] reported that the petrous bone reaches approximately $46 \%$ of its full size during the first two years of life, after which the growth rate slows markedly down until growth stops at approximately 20 years of age. In the present study, four petrous bones were removed from the total sample as they were from sub-adults (actual ages were 7, 9, 14 and 17 years). However, we did measure the diameter and found that in three of four cases a correct sex determination was made (all the four petrous bones were from males and were determined as such except for the 17-year old male, where the diameter was measured to $3.5 \mathrm{~mm}$ and hence designated as "undecided"). This may point to a potential use of this method for sexing sub-adults. Indeed, we have since performed stable isotope analyses of prehistoric, adult, petrous bones and compared the results with readings from the femur and first molar, which showed that the isotopic values of the petrous bones where closer to the (fixed) dental enamel values than to the femur, indicating that growth and remodelling is altered different [123].

\section{ETHNICITY}

The various methods employed for ethnic origin include both metric and non-metric assessments. For example, computer programs have been developed which match certain craniofacial measures with a database, which contains craniofacial measures collated from osteological material of known ethnicity [124] However, the assessment of non-metric traits may be more subjective, as they cannot be discretely quantified, but rather reflect the investigators training and experience in identifying and recording these traits. Furthermore, when evaluating ethnicity it is probably exactly those non-metric traits which are least commonly seen by the investigator which may be the most crucial. In Denmark, for example, shovel shaped

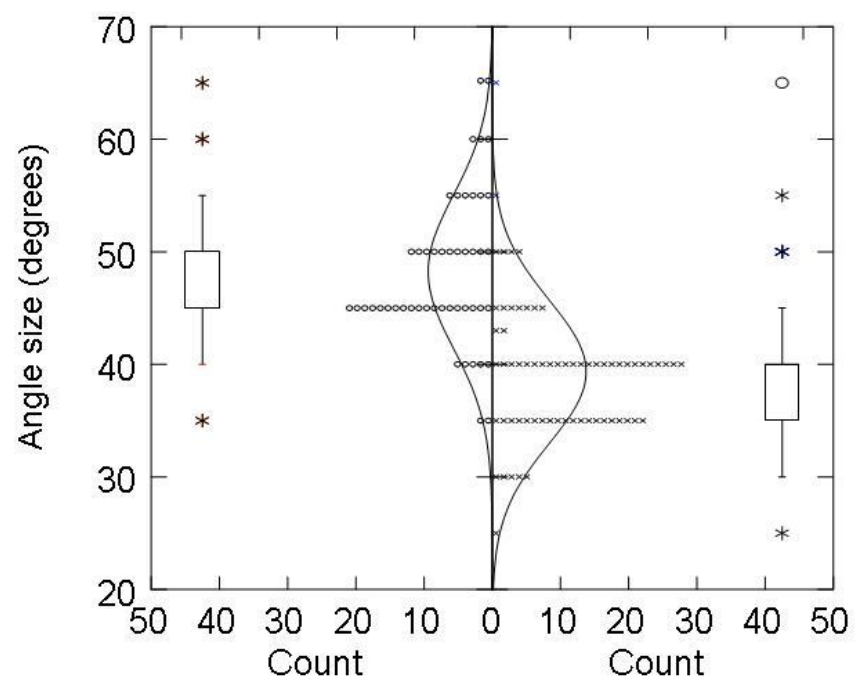

Figure 20. Distribution of lateral angle size by sex in the forensic sample: females left (open circles), males right (crosses). Circles and crosses at bar charts (females left, males right) indicate outliers.

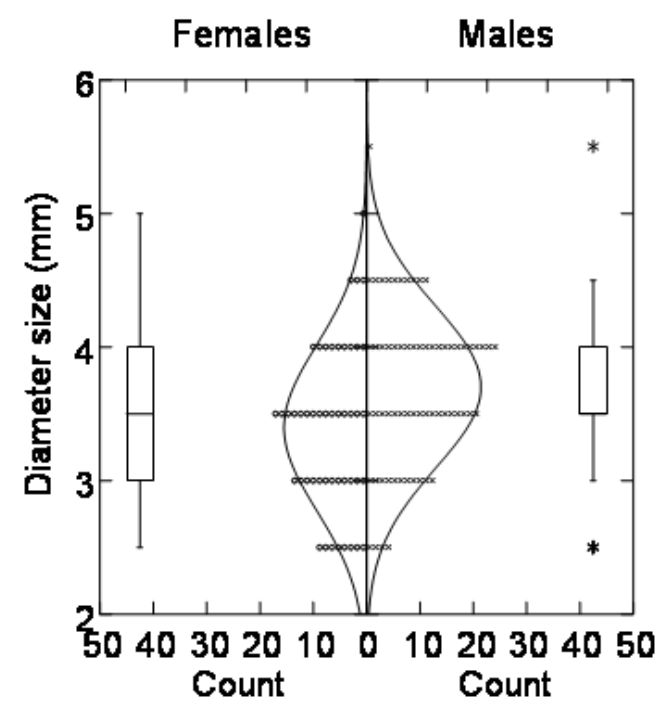

Figure 21. Combined boxplot and distribution plot (with normalized curves) of left side diameter by sex (unilateral sample).

incisors are rarely seen in ("Caucasian"/"White") population, but forensic identification cases may involve the remains of purported Greenlanders ("Inuit"/Mongoloid"), who often have these traits. Thus a Danish forensic odontologist, with a Danish odontological training, may simply not have much experience in discerning these traits. This may be remedied by studying skeletal collections which include material of varied ethnicity. While such collections do exist, especially in North America most European collections tend to be of historical and archaeological nature [125].

Yet, in terms of forensic anthropological identification, determination of geographical origin or ethnicity may be important, especially in terms of investigative efforts by the police. We have applied some of the most 
commonly used metric and non-metric analyses on a skeletal collections, with special consideration for Greenlandic geographical origin, as experience has shown this to be one of the more common questions concerning ethnicity of human remains in Denmark. With the general flux in present day populations, i.e. immigration from East Europe, Middle Eastern countries and Africa, this will change, and it may be foreseen that the determination of ethnicity and geographical origin will become ever more difficult, and also in sense ever more non-sensical [126]. Still, at this point in time, we regularly do have cases where geographical origin becomes essential for further investigations as to identity, so a continued awareness and training in the area is important.

\subsection{The Laboratory of Biological Anthropology skeletal collection (Paper IX)}

The purpose of our investigation was to apply some of the methods used for evaluation of ethnicity on a large collection of historical and archaeological skulls, in order to evaluate the usefulness of an older anthropological skull collection concerning casework in terms of training and teaching. We recorded non-metric dental traits and performed craniometric analyses and cross checked our results with ethnic provenance. The material belonged to different skull collections of our institute at the University of Copenhagen.

We evaluated three different ethnic groups; "Black", "Chinese" and "Eskimo". The skulls in the groups "Black" and "Chinese" were collected in the 17th and 18th century. Most only had a general geographic descriptor as "Africa”, "China”, or a general racial descriptor as "Black”, "Chinese". The Eskimo material was excavated in Greenland during 17th-18th century. In our collection we have both archaeological pre-colonial Eskimo material (i.e. prior to $1721 \mathrm{AD}$ ), as well as post-colonial Eskimo material (postdating $1721 \mathrm{AD}$ ). The post-colonial population might reflect the present Eskimo population better as it is known that there has been significant commingling between Europeans and Inuit $[127,128]$. We therefore specifically chose the more recent 17th and 18th century for this study. In all, 80 skulls were analysed; 26 Greenland Eskimos; 29 "Africans"/"Blacks"; and 25 "Asians"/"Chinese or Malay".

The nature of the study was thus a morphometric and morphological investigation of anatomical and dental traits. Four non-metric dental traits were recorded for each skull: 1) shovel shape on upper central incisors, breakpoint 3-6 (c-f); 2) Carabelli's trait on upper first molars, breakpoint 5-7; 3) cusp number on lower second molars; and 4) enamel extensions on upper first molars. The standards of The Arizona State University Dental Anthropology System (ASU) were used for registration (Scott and Turner, 1997). Three non-metric cranial traits were recorded in the jaws; 1) palatal shape; 2) palatal torus; and 3) mandibular torus. Palatal shape was recorded to be either horseshoe shape, $v$-shape or parallel sided as described by Byers et al. [129]. Mandibular and palatal tori were recorded by the ASU system [130]. Nineteen cranial measures were taken following the programme manual [124], and the metric data was input in the FORDISC programme. The FORDISC programme computed a canonical discriminatory analysis for each skull and thereby assigned the skull to the most probable ethnic category. The programme assigns both sex and ethnicity, but in our results we have only tabulated the ethnicity. The programme allows scoring for various ethnic categories and it was decided to include scoring for the category "White", as several of the individuals may represent mixed ancestry.
The results for the non-metric traits showed that the traits generally followed the expected frequencies in overall $80 \%$ of the cases. The FORDISC programme correctly assigned ethnicity based on skull measures in overall $70 \%$ of the cases (Table 9). We thus find that this historical collection does show expected dental non-metric and craniometric traits. As such, the collection may be of value in forensic casework in terms of comparison and for teaching purposes.

\subsection{The frontal sinus (Paper III)}

The above metric and non-metric variables were all overt, and could be assessed or measured directly. Other structures or variables may be visualized by $\mathrm{X}$-ray. One such variable is the presence and morphology of the frontal sinus. The frontal sinus is easily visualized by $\mathrm{X}$-ray in dry skulls, and a number of publications have dealt with the worldwide difference in presence and size of the frontal sinus. Furthermore, since the very morphology of the frontal sinus displays high individuality, and because cranial $\mathrm{X}$-rays may exist from when a person was alive, the frontal sinus may be used to ascertain the identity of a deceased. The frontal sinuses appear in the second year of life, reaching the orbital roofs at 7 to 9 years of age and thereafter grow vertically up to the age of 15 years [131-134]. The frontal sinus is usually considered final in size by the age of 20 years [131].

The size and shape of the frontal sinus may be modified by disease, especially chronic sinusitis, which may lead to sclerotic bone formation along the margins $[132,135]$.

The frontal sinus size has earlier been investigated in Alaskan and Canadian Inuit skeletal materials $[136,137]$. These studies have shown a reduced frontal sinus size and a high absence frequency of the frontal sinus as compared to Caucasians. Studies on ethnic differences on frontal sinus size have shown the following frequencies for absence: Japanese: $13 \%$ in males and $23 \%$ in females; Bushmen: $11 \%$ in males and $11 \%$ in females; Caucasians: $10 \%$ in males and $10 \%$ in females [138]. In a study by Kritscher [139] the lowest frontal sinus size was reported for "Oceanoids" and Mongoloids, the highest for Caucasians with "Negroids" in between.

We performed a study to investigate whether Greenlandic Inuit had even smaller frontal sinuses, thus establishing a possible trend following the eastward migrations. The frontal sinus size was also examined in a modern Greenlandic material to investigate whether frontal sinus size had been subject to a diachronic change, which would be of special interest forensically. The material consisted crania from collection at the Laboratory of Biological Anthropology, University of Copenhagen. All the included crania had been determined archaeologically to be from the pre-European colonization period of Greenland, A.D. 1721 [140]. The modern material consisted of frontal X-rays taken of adult males and female Greenlandic Inuit

Table 9. Agreement between ethnicity as by morphometry (columns) versus label (rows).

\begin{tabular}{|c|c|c|c|c|c|}
\hline & "African" & "Asian" & "Inuit" & "European" & Total \\
\hline "Black" & 21 & 3 & 1 & 3 & 28 \\
\hline "Chinese" & 2 & 13 & 1 & 6 & 22 \\
\hline "Eskimo" & 1 & 4 & 19 & 1 & 25 \\
\hline Total & 24 & 20 & 21 & 10 & 75 \\
\hline
\end{tabular}


patients referred to treatment at the University Hospital of Copenhagen, Denmark.

The crania were X-rayed mounted in the Frankfurt-plane, with an alignment perpendicular to the $\mathrm{X}$-ray slide following earlier investigations [137]. The focus-to-slide and object-to-slide distances were uniform, with a magnification factor of approximately $1 \%$. The same $X$-ray apparatus was used throughout the study, and all X-rays were taken by the same radiologist. The frontal sinus as seen on $\mathrm{X}$-ray was traced on a digitizer to allow input to a standard desktop computer, with subsequent area calculation [141] (Figure 22). All X-rays were coded, thus allowing tracing and area calculation to be made in blind trials. Following earlier studies the inferior border of the frontal sinus was delimited by a baseline drawn tangentially to the superior borders of the orbits following earlier studies [133,136,137].

We found that while the area sizes for the (ancient) Greenlandic Inuit were smaller than the Alaskan area sizes, there was no apparent trend between the Canadian and Greenlandic samples, the Greenland males having a bigger area size than the Canadian males but vice versa for the females. However, when focusing on absence frequencies alone, there was significant differences between the ancient Greenlandic sample and the Alaskan and Canadian Inuit samples (males: $p=0.03$; females: $p=0.0001$ ). Likewise, there was a significant difference in absence frequencies between the ancient Greenlandic material and the recent (males: Chi-square $=12.01$; $p=0.0005$, females: Chi-square $=9.22 ; p=0.009$. There was also a significant sexual dimorphism in sinus area, females having smaller areas than males (Chi-square $=9.34 ; \mathrm{p}=0.0024$ ) (Table 10).

Among Mongoloids, the Inuit thus seem to have the highest abscence frequencies [136,137], and, as we found in our study, the ancient Greenland Inuit, having the highest absence frequencies among these, also had the highest absence frequencies ever recorded for a population group: $45 \%$ for males, $66.7 \%$ for females. The modern Greenlandic sample had statistically significant lower absence frequencies than the ancient sample, yet still one in five Greenland adults in our study had an absent frontal sinus extending above the supra-orbital line. Such a reduction in absence frequencies could be a result of modern, post-colonial admixture with Caucasians [127,128]. An absent or small frontal sinus may thus, along with other metric and nonmetric variables point to Greenland ancestry.

Underlying both the above studies (in terms of the labelling of the cases, as well as the tabulation of traits and measures by ethnic group) lies the question of race. On the other hand, geographical differences in dental and cranial traits and sizes do exist, but it cannot be seen as definite, discriminate groups, but rather as clinal differences. However, we do find that traits and cranial measures, as recorded for modern population groups, are reflected in our collections. This means that we can use our skull collection as a training material, as it does allow the forensic odontologist or anthropologist to see these traits and perform morphometrical analyses [e.g. 138]. It may ultimately be fitting that these skulls in the present may assist in better and faster identification of the dead, and not only be an example of racial prejudices in the past.

\section{CONCLUDING REMARKS}

\subsection{The present work}

Continued testing of anthropological methods for evaluating age at death, sex and ethnicity is of paramount importance for forensic anthropology. The present research shows that some published methods may be lacking in their basic definitions of what structures are analysed and in the way the analyses are carried out. Often, the intra- and inter-observer variation for a given method is bigger than anticipated. Naturally, this is to be expected as the

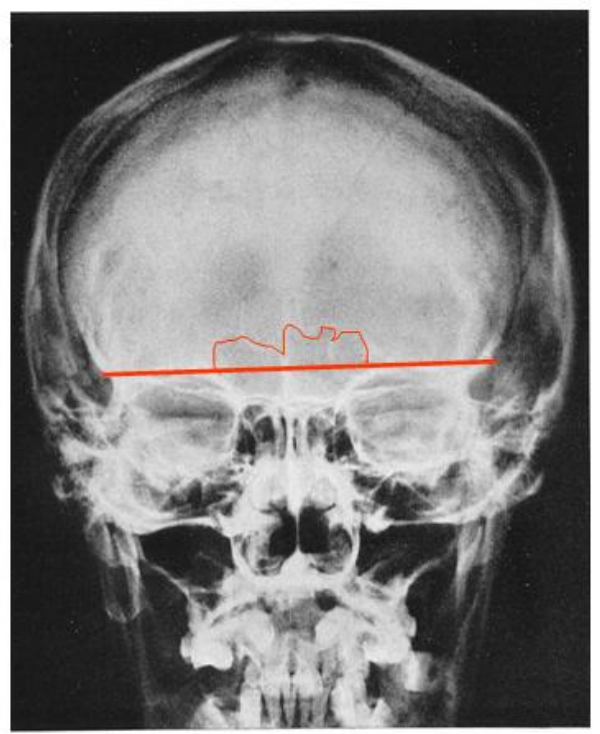

Figure 22. Radiograph of skull showing outlining of frontal sinus.

Table 10. Mean area size and absence frequencies. Data for Alaska and Canada from Koertvelyessy (1972) and Hanson and Owsley (1980) respectively.

\begin{tabular}{|l|c|c|c|c|c|}
\hline \multicolumn{1}{|c|}{ Sample } & $\mathrm{N}$ & area $\mathrm{x}\left(\mathrm{mm}^{2}\right)$ & 1 S.D. $\left(\mathrm{mm}^{2}\right)$ & frequency of absence $\mathrm{n} / \mathrm{N}$ pct. & frequency of absence 95\% C.I. \\
\hline Alaska males & 83 & 215 & - & $21 / 8325.3$ & $16.1-36.0$ \\
\hline Alaska females & 70 & 133 & - & $25 / 7035.7$ & $24.6-48.1$ \\
\hline Canada males & 70 & 94 & 153 & $30 / 7042.9$ & $31.1-55.3$ \\
\hline Canada females & 73 & 89 & 159 & $29 / 7339.7$ & $28.5-51.9$ \\
\hline Ancient Greenland males & 60 & 145 & 217 & $27 / 6045.0$ & $32.1-58.4$ \\
\hline Ancient Greenland females & 84 & 74 & - & $56 / 8466.7$ & $55.5-76.6$ \\
\hline Recent Greenland males & 17 & - & - & $3 / 1723.5$ & $6.8-49.9$ \\
\hline Recent Greenland females & 14 & - & $3 / 1421.4$ & $4.7-50.8$ \\
\hline
\end{tabular}


first publications usually deal with only one or two observers applying and developing the technique, and therefore becoming familiar and proficient with the technique. Also, applying a method on different populations will expectedly result in an increased variation. It is only the continued testing by other researchers, on other populations, and with a careful notification of intra- and inter-observer variation, that should lead such methods to be accepted.

The present work has addressed these issues by critically assessing the osteon method [II], trabecular bone loss in the femur [I] and the GreulichPyle method of wrist bone development [XIII]. The former was found to be lacking in definitions concerning the structures used, and it was shown how stereological methods may be applied to make the selection of structures and ROIs more unbiased [XI]. It is perhaps surprising how stereological methods, specifically developed for histopathology, seldom have been used in physical anthropological bone histomorphometry. As pertains to the well-known method of ecto-cranial suture closure, we tried to apply fractal geometry but we found no improvement over other methods: the sutures seemingly only show a limited correlation with age [VI], and perhaps more definitive analyses of cranial sutures still await more specific methods of quantification. We further investigated sexual dimorphism of skull thickness, but found this to be inconclusive, and thus not applicable in forensic anthropology [V, $\mathrm{VIII}]$ at least in terms of sex assessment. On the other hand, the lateral angle method did show a statistically significant sexual dimorphism [VII], as did the diameter of the internal meatus acusticus [X]. Using a historical skeletal collection, ethnicity was generally predicted correctly [IX]. It demonstrates that access to a skeletal collection where skeletons of individuals of different ethnicity are available may be important in training physical anthropologists and forensic odontologists. This collection was also used for determining frontal sinus size [III].

As for age, methods relying on absolute chronology would be preferable. We have tried to apply amino acid racemisation [IV], which though still leaves room for error given its dependence on temperature (as it is fundamentally a chemical reaction). To our knowledge, the only method for achieving absolute dating of an individual's birth year, and hence age, are methods relying on radiocarbon dating, in turn due to massive changes in the atmospheric content of ${ }^{14} \mathrm{C}$. First used on teeth, we have applied this method on eye lenses, as the eye lens proteins are not substituted, which along with dental enamel, is unique for the body $[\mathrm{XII}, \mathrm{XIV}]$.

\subsection{Aspects of future work}

More research on absolute dating methods, with a view to narrow down dating to single amino acids, or specific parts of the skeleton, e.g., ear bones or the petrosal bone [123] may make this method more applicable in those cases were teeth or eye lenses are not preserved. Future work would also include further development of non-biological marker based methods. Thus, other radioactive isotopes which are up-taken by the living individual, and which in life are in equilibrium, should be investigated. One such isotope is Radon, found in high levels in certain geographical areas, and often in buildings built with concrete. Potentially, the uptake of Radon by breathing and its subsequent atomic degradation may be applied to time of death determination. Based on my research on ${ }^{14} \mathrm{C}$, I intend to pursue this venue of research.

Another main problem in forensic anthropology, largely unaddressed, is how to integrate the results of several methods, e.g., when performing age evaluation. In a usual forensic case, the anthropologist may end up using several methods for ascertaining age, each yielding a slightly different age estimate. Simply calculating a mean, or designating the lowest and highest age for any of the methods and presenting this as a combined result is not mathematically or statistically satisfactory. Although so-called combined methods have been described before $[15,60]$ these combined methods have relied on using specific methods in a specific setup. Important new steps have been taken based on the so-called Rostock manifest, which aims at improving ageing methods and their analysis [142]. Specifically, Boldsen et al. have contributed to the aspect of combining various age estimates with transition analysis [143]. The method has been applied and tested on several archaeological materials, and has until now incorporated assessment of cranial sutures, symphyseal and auricular changes. Future research should try to use other ageing methods, e.g., wrist X-ray, dental assessment, in this format, in terms of better assessing age (and error) for determining age of the living.

Finally, the existence of comparative skeletal collections is important, not least as access to larger samples may, e.g., result in more data on age changes, which may give a better so-called "coverage" of a given method [see e.g., 144]. Ultimately, the development of new methods relies on such collections. Some collections do have more specific data, including age and sex as well as other factors, e.g. disease status, recorded for each skeleton, while others are more ethnographical or archaeological nature, meaning this data is not available. Future trends might well see such collections being made available over the net, e.g., by high-resolution CT-scanning of the skeletons, and thus building virtual libraries, allowing researchers easier access. As such, visualisation of bone morphology using CT-scan, surface laser scan, etc. may help in making anthropological methods more uniform in their application, as e.g., visual definitions of stages of change, may be disseminated digitally (in confront to the present use of descriptive texts, 2D pictures, or casts) [145]. Digital rendering of bone structures will also have spin-offs in the forensic anthropological analysis of trauma [114,115], and may further constitute a first step in a future trend to use CT-scanning and 3D-techniques not merely for visualization, but also to develop dynamic, finite element analyses of cranial fractures. 


\section{THE WORK IS BASED ON THE FOLLOWING PUBLISHED PAPERS:}

I. Lynnerup N, Thomsen I, Frøhlich B, 1990. A Non-invasive Method for Age at Death Determination. Medicine, Science and the Law, 30(4): 317-20.

II. Lynnerup N, Thomsen JL, Frøhlich B. 1998. Intra- and inter-observer variation in histological criteria used in age at death determination based on femoral cortical bone. Forensic Science International, 91: 219-30.

III. Lynnerup N, Homøe P, Skovgaard LT, 1999. The frontal sinus in ancient and modern Greenlandic Inuit. International Journal of Anthropology, 14: 47-54.

IV. Wöhler M, Jakobsen J, Sejrsen B, Lynnerup N, Dissing J, 2000. Estimation of Age at Death from Measurements of Aspartic Acid Racemization. Nordisk Rettsmedisin, 6: 57-59.

V. Lynnerup N, 2001. Cranial thickness in relation to age, sex and general body build in a Danish forensic sample. Forensic Science International, 117: 45-51.

VI. Lynnerup N, Brings Jakobsen JC, 2003. Age and Fractal Dimensions of Human Sagittal and Coronal Sutures. American Journal of Physical Anthropology, 121 332-336.

VII. Norén A, Lynnerup N, Czarnetzki A, Graw M. 2005. The Lateral Angle: A Method for Sexing Using the Petrous Bone. American Journal of Physical Anthropology, 128(2): 318-323.

VIII. Lynnerup N, Astrup JG, Sejrsen B. 2005. Thickness of the cranial trabecular bone layer in relation to age, sex and general body build. Head \& Face Medicine, 1: 13 (22 pp) (Biomed Central).
IX. Sejrsen B, Lynnerup N, Hejmadi M. 2005. A historical skull collection and its use in forensic odontology and anthropology. Journal of Forensic Odonto-Stomatology, 23(2): 40-44

X. Lynnerup N, Schultz M, Madelung A, Graw M. 2006. Diameter of the Human Internal Acoustic Meatus and Sex Determination. International Journal of Osteoarchaeology, 16: 118-123.

XI. Lynnerup N, Frohlich B, Thomsen JL. 2006. Assessment of age at death by microscopy: Unbiased quantification of secondary osteons in femoral cross sections. Forensic Science International, 159 (suppl. 1): 100-103.

XII. Lynnerup N, Kjeldsen H, Heegaard S, Jacobsen C, Heinemeier J. 2008. Radiocarbon Dating of the Human Eye Lens Crystallines Reveal Proteins without Carbon Turnover throughout Life. PLoS ONE. Jan 30;3(1):e1529.

XIII. Lynnerup N, Belard E, Buch-Olsen K, Sejrsen B, Damgaard-Pedersen K, 2008. Intra- and interobserver error of the Greulich-Pyle method as used on a Danish forensic sample. Forensic Science International, 179(2-3): 242.e1-6.

XIV. Lynnerup N, Kjeldsen H, Zweihoff R, Heegaard S, Jacobsen C, Heinemeier J., 2010. Ascertaining year of birth/age at death in forensic cases: A review of conventional methods and methods allowing for absolute chronology. Forensic Science International, 201(1-3): 74-8.

\section{REFERENCES}

[1] Lynnerup N, 2009. Retsantropologi. Ugeskrift for Læger; 171: 2643-5.

[2] Reppien K, Sejrsen B, Lynnerup N, 2006. Evaluation of post-mortem estimated dental age versus real age: A retrospective 21-year survey. Forensic Science International, 159 Suppl 1: S84-8.

[3] Andersen L, Lynnerup N. 2008. Unidentified bodies brought to the Section of Forensic Pathology, University of Copenhagen. Scandinavian Journal of Forensic Science, 14(1):10-13.

[4] Lynnerup N, Jakobsen J, 1998. Personidentifikation ud fra kranierøntgen. Nordisk Rettsmedisin, 4: 76-77.

[5] Buikstra JE, Ubelaker DH, 1984. Standards for Data Collection from Human Skeletal Remains. Arkansas Archaeological Survey Research Series, 44. Arkansas, U.S.A.

[6] Krogman WM, Iscan MY, 1986. The Human Skeleton in Forensic Medicine. Charles C Thomas, Illinois, U.S.A.Lovejoy CO, MeindI RS, Pryzbeck TR, Mensforth RP, 1985. Chronolongical metamorphosis of the auricular surface of the ilium: A new method for the determination of adult skeletal age at death. American Journal of Physical Anthropology; 68: 15-28.

[7] Knussman R, 1988. Anthropologie. Handbuch der vergleichenden Biologie des Menschen I. Begründet von R. Martin. Gustav Fisher Verlag, Stuttgart, Germany.

[8] Cunha E, Baccino E, Martrille L, Ramsthaler F, Prieto F, Schuliar Y, Lynnerup Y, Cattaneo C. 2009. The problem of aging human remains and living individuals: A review. Forensic Science International, 193(1-3):1-13. doi:10.1016/j. forsciint.2009.09.008

[9] Lynnerup N, Sejrsen B, Hougen HP, 2006b. Age Evaluation of the living. How? How many? How good? Abstract. 16th Nordic Conference on Forensic Medicine, Turku, Finland.
[10] Ubelaker $\mathrm{DH}, 1989$. Human skeletal remains. Smithsonian Institution, Washington D.C., U.S.A.

[11] Stewart TD, 1979. Essentials of Forensic Anthropology, Especially as developed in the United States. Charles C. Thomas, Springfield, U.S.A.

[12] Ferembach D, Schwidetzky I, Stloukal M, 1980. Recommendations for Age and Sex Diagnoses of Skeletons, "Workshop of European anthropologists". Journal of Human Evolution; 9: 517-549.

[13] Scheuer L, Black S, 2000. Developmental Juvenile Osteology. Academic Press, New York, U.S.A.

[14] Mays S, 1998. The Archaeology of Human Bones. Routledge, London, U.K.

[15] Lovejoy CO, Meindl RS, Mensforth RP, Barton TJm 1985. Multifactorial determination of skeletal age at death: a method and blind tests of its accuracy. American Journal of Physical Anthropology, 68(1): 1-14.

[16] Buckberry JL, Chamberlain AT, 2002. Age estimation from the auricular surface of the ilium: a revised method. Am J Phys Anthropol.; 119(3): 231-9.

[17] Todd TW, 1920. Age Changes in the Pubic Bone. I. The Mael White Pubis. American Journal of Physical Anthropology; 3: 285-339.

[18] Katz D, Suchey JM, 1986. Age determination of the male os pubis. Am J Phys Anthropol.; 69(4): 427-35

[19] Suchey JM, Brooks ST, Katz D. 1988. Instructions for the use of the Suchey-Brooks system for age determination of the female os pubis. France Casting.

[20] Iscan MY, Loth SR, Wright RK, 1984. Metamorphosis at the sternal rib: A new method to estimate age at death in males. American Journal of Physical Anthropology; 65: 147-156.

[21] Waldron T, Rogers, J. 1991. Inter-observer variation in coding osteoarthritis in human skeletal remains. International Journal of Osteoarchaeology, 2:235-241. 
[22] Felson DT, 1988. Epidemiology of hip and knee osteoarthritis. Epidemiologic Reviews, 10:1-28.

[23] Todd TW, Lyon DW, 1924. Cranial suture closure its progress and age relationship. Part 1 - adult males of white stock. Am J Phys Anthropol; 7(3): 325-384.

[24] Perizonius WRK, 1984. Closing and Non-closing Sutures in 256 Crania of Known Age and Sex from Amsterdam (A.D. 1883-1909). J Hum Evol; 13: 201-216.

[25] Meindl RS, Lovejoy CO, 1985. Ectocranial suture closure: a revised method for the determination of skeletal age at death based on the lateral-anterior sutures. Am J Phys Anthropol; 68(1): 47-56.

[26] Key CA, Aiello LC, Molleson T, 1994. Cranial Suture Closure and its Implications for Age Estimation. International Journal of Osteoarchaeology; 4(3): 193-208.

[27] Hauser G, Manzi G, Vienna A, DeStefano G, 1991. Size and Shape of Human Cranial Sutures A new Scoring Method. Am J Anat; 190: 231-244.

[28] Liebovitch LS. 1998. Fractals and Chaos. New York and Oxford: Oxford University Press.

[29] Hartwig WC. 1991. Fractal Analysis of Sagittal Suture Morphology. J Morphol 210: 289-298.

[30] King RB, Weissman LJ, and Bassingthwaighte JB. 1990. Fractal Descriptions for Spatial Statistics. Ann Biomed Eng 18: 111-121.

[31] Liebovitch LS, and Toth T. 1989. A fast algorithm to determine fractal dimensions by box counting. Phys Lett A 141: 386-390

[32] Yu JC, Wright RL, Williamson MA, Braselton JP 3rd, Abell ML. 2003. A fractal analysis of human cranial sutures. Cleft Palate Craniofac J.; 40(4): 409-15.

[33] Skrzat J, Walocha J. Fractal dimensions of the sagittal (interparietal) sutures in humans. Folia Morphol (Warsz). 2003 May;62(2):119-22.

[34] Kerley ER, 1965. The microscopic determination of age in human bone. American Journal of Physical Anthropology; 23: 149-163.

[35] Ahlquist J, Damsted O, 1969. A modification of Kerley's method for the microscopic determination of age in human bone. Journal of Forensic Sciences, 14 (1969) 205-212.

[36] Singh I, Gunberg GL, 1970. Estimation of age at death in human males from quantitative histology of bone fragments. American Journal of Physical Anthropology; 33: 373-382

[37] Bouvier M, Ubelaker DH, 1977. A Comparison of two Methods for the Microscopic Determiantion of Age at Death. American Journal of Physical Anthropology; 46 391-394.

[38] Kerley ER, Ubelaker D, 1978. Revisions in the microscopic method of estimating age at death in human cortical bone. American Journal of Physical Anthropology; 49: 545-546.

[39] Thompson DD, 1979. The core technique in the determination of age at death in skeletons. Journal of Forensic Sciences; 24: 902-915.

[40] Uytterschaut HT, 1985: Determination of Skeletal Age by Histological Methods. Zeitung Morphol. Anthropol.; 75(3): 331-340.

[41] Drusini A, 1987. Refinements of two methods for the histomorphometric determination of age in human bone. Zeitung Morph. Anthrop.; 77(2): 167-176.

[42] Samson S, Branigan K, 1987. A new method of estimating age at death from fragmentary and weathered bone. In A. Boddington, A.N. Garland and R.C. Janaway (eds): Death, Decay and Reconstruction. Approaches to Archaeology and Forensic Science. Manchester: Manchester University Press, pp. 101-108.

[43] Ericksen MF, 1991. Histologic Estimation of Age at Death Using the Anterior Cortex of the Femur. American Journal of Physical Anthropology; 84: 171-79.

[44] Yoshino M, Imaizumi K, Miyasaka S, Seta S, 1994. Histological estimation of age at death using microradiographs of humeral compact bone. Forensic Science International; 64: 191-198.
[45] Pfeiffer S, 1980. Bone remodelling age estimates compared with estimates by other techniques. Current Anthropology; 21: 793-4.

[46] Lazenby RA, 1982-84. Inherrent deficiencies in cortical bone microstructural age estimation techniques; Ossa 9-11: 95-103.

[47] Stout SD, 1978. The use of histomorphology to estimate age. Journal of Forensic Science; 33(1): 121-5.

[48] Martin DL, Goodman AH, Armelagos GJ, 1981. On the use of microstructural bone for age identification. Current Anthropology; 22: 437-8.

[49] White T, 1991. Human Osteology. Academic Press, San Diego, California, U.S.A.

[50] Pfeiffer S, Lazenby R, Chiang J, 1995. Brief Communication: Cortical Remodelling Data Are Affected by Sampling Location. American Journal of Physical Anthropology; 96: 89-92.

[51] Stout SD, Gehlert SJ, 1980. The relative accuracy and reliability of histological aging methods. Forensic Science International; 15: 181-190.

[52] Bland JM, Altman DG, 1986. Statistical methods for assessing agreement between two methods of clinical measurement. Lancet; 8476: 307-310.

[53] Frost HM, 1987a. Secondary Osteon Populations: An Algorithm for Determing Mean Bone Tissue Age. Yearbook of Physical Anthropology; 30: 221-238.

[54] Frost HM, 1987b. Secondary Osteon Densities: An Algorithm for Estimating the Missing Ostoens. Yearbook of Physical Anthropology; 30: 239-254.

[55] Abou-Arab M, Thomsen JL, Frøhlich B, Lynnerup N, 1995. Histological staining of secondary osteons. American Journal of Physical Anthropology, 98: 391-4.

[56] Gundersen HJG, Bendtsen TF, Korbo L, Marcussen N, Møller A, Nielsen K, Nyengaard JR, Pakkenberg B, Sørensen FB, Vesterby A, West MJ, 1988. Some new, simple and efficient stereological methods and their use in pathological research and diagnosis. Acta Pathologica, Microbiologica et Immunologica Scandinavica; 96: 379-94.

[57] Villa C, Lynnerup N. 2010. Technical note: A stereological analysis of the cross-sectional variability of the femoral osteon population. Am J Phys Anthropol.;142(3): 491-6.

[58] Hansen G, 1954. Die alterbestimmung am proximalen humerus und femurende in rahmen der identifizierung menschlicher skeltreste. Wissenschaftliche Zeitschrift der Humboldt-Universität zu Berlin, Mathematisch-naturwissenschaftliche Reihe $3,1-73$

[59] Schranz D, 1959. Age Determinstion from the Internal Structure of the Humerus. American Journal of Physical Anthropology, 17: 273-278.

[60] Acsadi G, Nemeskeri J, 1970. History of Human Life Span and Mortality. Academia Kiado, Hungary: $346 \mathrm{pp}$

[61] Macchiarelli R, Bondioli L, Frohlich B, Weaver DS, 1987. L'indagine radiografica dello scheletro nella attribuzione dell'eta alla morte. Un analisi densitometrica sperimentale. Revista di Antropologia LXV, 309-346.

[62] Greulich WW, Pyle SI, 1959. Radiographic atlas of skeletal development of the hand and wrist, Stanford University Press, California.

[63] Kemperdick H, 1981. Skelettaler-Bestimmung bei Kindern mit normalem und abweichendem Wachtstumverlauf, Fortschritte der Medizin; 99: 152-6.

[64] Vignolo M, Milani S, Dibattista E, Naselli A, Mostert M, Aicardi G, 1990. GreulichPyle, Tanner-Whitehouse and Roche-Wainer-Thissen (knee) methods for skeletal age assessment in a group of Italian children and adolescents, Eur. J. Pediatr; 149 314-17.

[65] Groell R, Lindbichler F, Riepl T, Gherra L, Roposch A, Fotter R, 1999. The reliability of bone age determination in central European children using the Greulich and Pyle method. Brit J Radiol; 72: 461-4.

[66] Cameron N, 2004. Measuring maturity, in: R. C. Hauspie, N. Cameron, L. Molinari (Eds.) Methods in Human Growth Research, Cambridge University Press, Cambridge, pp. 68-107. 
[67] Tanner JM, 1955. Growth at adolescence, Blackwell scientific publications, Oxford, U.K.

[68] Roche AF, Chumlea WC, Thissen D, 1988. Assessing the Skeletal Maturity of the Hand - Wrist: Fels Method, C. C. Thomas, Springfield, III., U.S.A

[69] Thodberg HH, Lomholt JF, Kreiborg S, 2007. Automated Determination of Skeletal Maturity. In: Abstracts of Lectures and Posters, European Orthodontic Society, 83rd Congress Berlin, Germany, 20-24 July (2007) 37-38.

[70] Schmeling A, Geserick G, Reisinger W, Olze A, 2007. Age estimation. For Sci Int; 165: 178-181.

[71] Lynnerup N, Kjeldsen H, Zweihoff R, Heegaard S, Jacobsen C, Heinemeier J. 2010. Ascertaining year of birth/age at death in forensic cases: A review of conventional methods and methods allowing for absolute chronology. Forensic Sci Int.; 201 (1-3): 74-8.

[72] Helfman PM, Bada JL, 1975. Aspartic acid racemization in tooth enamel from living humans. Proc. Natl. Acad. Sci.; 72: 2891-2894.

[73] Helfman PM, Bada JL, 1976. Aspartic acid racemisation in dentine as a measure of ageing. Nature; 262: 279-281.

[74] Ohtani S, Yamamoto K, 1991. Age estimation using the racemization of amino acid in human dentin. J. Forensic Sci.; 36: 792-800.

[75] Mörnstad H, Pfeiffer H, Teivens A, 1994.Estimation of dental age using HPLCtechnique to determine the degree of aspartic acid racemization. J. Forensic Sci. 39: 1425-1431.

[76] Ritz S, Schütz HW, 1993. Aspartic acid racemization in intervertebral discs as an aid to postmortem estimation of age at death. J. Forensic Sci.; 38: 633-640.

[77] Ritz S, Turzynski A, Schütz HW, 1994. Estimation of age at death based on aspartic acid racemization in noncollagenous bone protein. Forensic Sci. Int.; 69: 149-159.

[78] Schmeling A, Olze A, Reisinger W, Geserick G, 2005. Forensic age estimation and ethnicity (Letter). Leg Med; 7: 134-137.

[79] Masters PM, Bada JL, 1977. Aspartic acid racemisation in the human lens during ageing and in cataract formation. Nature; 268: 71-73.

[80] Masters PM, 1986. Age at death determinations for autopsied remains based on aspartic acid racemization in tooth dentin: importance of postmortem conditions. Forensic Sci Int.; 32: 179-184.

[81] Carolan VA, Gardner ML, Lucy D, Pollard AM, 1997. Some considerations regarding the use of amino acid racemization in human dentine as an indicator of age at death. J. Forensic Sci.; 42: 10-16.

[82] Spalding KL, Buchholz BA, Bergman L-E, Druid H, Frisen J, 2005. Age written in teeth by nuclear tests. Nature; 437: 333-4.

[83] Hedges RE, Clement JG, Thomas CD, O'Connell TC, 2007. Collagen turnover in the adult femoral mid-shaft: modeled from anthropogenic radiocarbon tracer measurements. Am J Phys Anthropol.; 133: 808-16.

[84] Bhardwaj RD, Curtis MA, Spalding KL, Buchholz BA, Fink D, Björk-Eriksson T, et al. 2006. Neocortical neurogenesis in humans is restricted to development. Proceedings of the National Academy of Sciences; 103(33): 12564-8.

[85] Bebe DC, 2003. The Lens. In: Adler's Physiology of the Eye (Kaufman PL \& Alm A eds.). Mosby Inc.: St. Louis. 117-158.

[86] De Vries H, 1985. Atomic Bomb Effect: Variation of Radiocarbon in Plants, Shells, and Snails in the Past 4 Years. Science ; $128: 250-251$

[87] Levin I, Kromer B, 2004. The tropospheric $14 \mathrm{CO} 2$ level in mid-latitudes of the Northern Hemisphere (1959-2003). Radiocarbon ; 206 : 1261-1272.

[88] Goodsite ME, Rom W, Heinemeier J, Lange T, Ooi S, Appleby PG, et al., 2001. High-resolution AMS $14 \mathrm{C}$ dating of post-bomb peat archives of atmospheric pollutants. Radiocarbon; 43: 495-515.
[89] Kueppers L, Southon J, Baer P, Harte J, 2004. Dead wood biomass and turnover time, measured by radiocarbon, along a subalpine elevation gradient. Oecologia; 141(4): 641-51.

[90] Jim S, Ambrose SH, Evershed RP, 2004. Stable carbon isotopic evidence for differences in the dietary origin of bone cholesterol, collagen and apatite: Implications for their use in palaeodietary reconstruction. Geochim Cosmochim Ac.; 68(1): 61-72.

[91] Tripp JA, McCullagh JSO, Hedges REM, 2006. Preparative separation of underivatized amino acids for compound-specific stable isotope analysis and radiocarbon dating of hydrolyzed bone collagen. Journal of Separation Science; 29(1): 41-8.

[92] Lynnerup N, Holck P. 2008. Retsantropologi. In: Biologisk antropologi med human osteologi (Lynnerup N, Bennike P, Iregren E, eds.). Gyldendal, Copenhagen, Denmark: p: 425-433.

[93] Bass WM, 1987. Human Osteology. A Laboratory and Field Manual. Missouri Archaeological Society, U.S.A.

[94] Anderson RJ, 1882. Observations on the thickness of the human skull. Dublin J. Med. Sci.; 74: 270-280.

[95] Todd TW, 1924. Thickness of the male white cranium, Anat. Record; 27: 245-256.

[96] Angel L, 1971. Skull vault thickness variation. Am. J. Physical Anthrop.; 35: 272.

[97] Schmitt HP, Saternus KS, 1973. BeitraÈge zur forensischen Osteologie. III. Zur Frage der Bestimmung des Individualalters an Hand der Dicke der SchaĖdelkalotte, Zeitschrift fuÈr [Rechtsmedizin; 72: 40-49.

[98] Ross MD, Lee KA, Castle WM, 1976. Skull thickness of black and white races. South African Med. J.; 50(16): 635-638.

[99] Einy S, Smith P, Becker A, 1984. On the measurement of cranial thickness at nasion on cephalographs. Am. J. Physical Anthrop.; 65(3): 313-314.

[100] Pensler J, McCarthy JG, 1985. The calvarial donor site: an anatomic study in cadavers. Plastic Reconstructive Surgery; 75(5): 648-651.

[101] Ishida H, Dodo Y, 1990. Cranial thickness of modern and Neolithic populations in Japan. Human Biol.; 62(3): 389-401.

[102] Ross AH, Jantz RL, McCormick WF, 1998. Cranial thickness in American females and males. J. Forensic Sci.; 43(2): 267-272.

[103] Hansman CF, 1966. Growth of interorbital distance and skull thickness as observed in roentgenographic measurements. Radiology; 86(1): 87-96.

[104] Smith P, Wax Y, Becker A, Einy S, 1985. Diachronic variation in cranial thickness of near eastern populations. Am. J. Physical Anthrop.; 67: 127-133.

[105] Israel H, 1973. Age factor and the pattern of change in craniofacial structures, Am J. Physical Anthrop.; 39: 111-128.

[106] Tallgren N, 1974. Neurocranial morphology and aging $Ð$ a longitudinal roentgen cephalometric study of adult Finnish women; Am. J. Physical Anthrop.; 41: 285294.

[107] Adeloye A, Kattan K, Silverman F, 1975. Thickness of the normal skull in the American blacks and whites. Am. J. Physical Anthrop.; 43: 23-30.

[108] Hwang K, Hollinger JO, Chung RS, Lee SI, 2000. Histomorphometry of parietal bones versus age and race. J Craniofac Surg; 11:17-23.

[109] Jung YS, Kim HJ, Choi SW, Kang JW, Cha IH, 2003. Regional thickness of parietal bone in Korean adults. Int J Oral Maxillofac Surg; 32:638-641.

[110] Lynnerup N, Lynnerup O, 1993. Automatic data acquisition of anthropological measurements. Comp. Biol. Med.; 23: 143-147.

[111] Roche AF, 1953. Increase in cranial thickness during growth. Human Biol.; 25: 81-92.

[112] Hershkovitz I, Greenwald C, Rothschild BM, Latimer B, Dutour O, Jellema LM, WishBaratz S, 1991. Hyperostosis Frontalis Interna: An Anthropological Perspective. American Journal of Physical Anthropology; 109: 303-325. 
[113] Gurdjian ES, Webster JE, Lissner HR, 1950. The mechanism of skull fracture. Radiology; 54: 313-339.

[114] Jacobsen C, Bech BH, Lynnerup N. 2009. A comparative study of cranial, blunt trauma fractures as seen at medicolegal autopsy and by Computed Tomography BMC Medical Imaging 2009, 9:18

[115] Jacobsen C, Lynnerup N. 2009. Craniocerebral trauma - Congruence between post-mortem computed tomography diagnoses and autopsy results. A 2-year retrospective study. Forensic Science International; 194(13): 9-14

[116] Galloway A, Willey, Synder L. 1997. human bone mineral densities and survival of bone elements: A contemporary study. In: Haglund WD, Sorg MH (eds.): Forensic taphonomy: The post-mortem fate of human remains. New York, CRC Press: 295317.

[117] Waldron T, 1987. The realtive survival oft he human skeleton: Implications for paleopathology. In: Boddignton A, Garland AN, Janaway RC (eds.). Death, decay and reconstrcution. Approaches to archaeology and forensic science. Manchester University Press, Manchester, U.K., 55-64.

[118] Wahl J.1982. Ein Beitrag zur Geschlechtdiagnose von Leichenbrandmaterial anhand der Pars petrosa. Praehist Zschrft 57, 97-119.

[119] Graw M, Schulz M, Wahl J. 2003. A simple morphological method for gender determination at the petrous portion of the os temporalis. Forensic Sci Int 136 Suppl.1: 165-166.

[120] Wahl J. 1981. Ein Beitrag zur metrischen Geschlechtsdiagnose verbrannter und unverbrannter menschlicher Knochenreste-ausgearbeitet an der Pars petrosa ossis temporalis. Z Rechtmed 86: 79-101.

[121] Ahlbrecht M. 1997. Geschlechtsdifferenzierung an der Pars petrosa ossis temporalis. Inaugural-Dissertation zur Erlangung des Doktorgrades de Zahnheilkunde der Medizinischen Fakultät der Eberhard-Karls-Universität Tübingen (in German).

[122] Schmid HM, Dahm P. 1977. Die postnatale Entwicklung des menschlichen Os temporale. Gegenbaurs morphologisches Jahrbuch 123/3: 485-513.

[123] Jørkov ML, Heinemeier J, Lynnerup N, 2009. The Petrous Bone - A new sampling site for identifying early dietary patterns in stable isotopic studies. American Journal of Physical Anthropology, 138(2): 199-209.

[124] Jantz RL, Ousley SD, 1993. FORDISC 1.0. Computerized forensic discriminant functions. University of Tennessee, Knoxville, U.S.A.

[125] Quigley C, 2001. Skulls and Skeletons. Human Bone collections and Accumulations. McFarland and Co. Publishers, North Carolina, U.S.A. Pp. 263

[126] Goodman A, 1995. The problematic of "Race" in contemporary biological anthropology. In: Biological Anthropology. The state of the science, Eds. Boaz NT \&Wolfe LD. International Institute of Human Evolutionary Research, Oregon State University Press. p. 241-50.

[127] Saillard J, Forster P, Lynnerup N, Bandelt HJ, Nørby S, 2000. mtDNA Variation among Greenland Eskimos: The Edge of the Beringian Expansion. American Journal of Human Genetics, 67: 718-726.
[128] Bosch E, Calafell F, Rosser ZH, Nørby S, Lynnerup N, Hurles ME, Jobling MA, 2003. High level of male-based Scandinavian admixture in Greenlandic Inuit shown by Y-chromosomal analysis. Human Genetics, 112: 353-363.

[129] Byers SN, Churchill SE, Curran B. 1997. Identification of Euro-Americans, AfroAmericans, and Amerindians from palatal dimensions. J Forensic Sci, 42(1): 3-9.

[130] Kelly MA, Spencer Larsen C. 1991. Advances in Dental Anthropology, Wiley-Liss, New York.

[131] Evans KT, Knight B, 1981. Forensic Radiology. London: Blackwell Scientific Publications.

[132] Maresh MM, 1940. Paranasal sinuses from birth to late adolescence. americal journal of Disease of Children, 60: 55-78.

[133] Francis P, Raman R, Korula P, Korah I, 1990. Pneumatization of the Paranasal Sinuses (Maxillary and Frontal) in Cleft Lip and Palate. Arch Otolaryngol Head Neck Surg.; 116:920-922.

[134] Brown WA, Molleson TI, Chinn S, 1984. Enlargement of the frontal sinus. Ann. Hum. Biol.; 11:221-226.

[135] Schüller A, 1921. Das Röntgenogramm der Stirnhöhle - ein Hilfsmittel für die Identitätsbestimmung von Schädeln. Mona-tenschrift Ohrenheilkunde; 55 (suppl.): 1617-1620 [in German].

[136] Koertvelyessy T, 1972. Relationships between the Frontal sinus and Climatic Conditions: A skeletal approach to Cold Adaptation. Am. J. Phys. Anthrop.; 37: 161-172.

[137] Hanson CL, Owsley DW, 1980. Frontal sinus size in Eskimo Populations. Am. J. Phys. Anthrop.; 53:251-255.

[138] Yoshino M, Miyasaka S, Sato H, Seta S, 1987. Classification system of frontal sinus patterns by radiography. Its application to identification of unknown skeletal remains. For. Sci. Int.; 34: 289-299.

[139] Kritscher H, 1983. Grössen- und Formvarianten der Stirnhöhlen bei einzelnen Rassen des Menschen. Mitt. Anthrop. Ges. Wien; 113:45-49 [in German].

[140] Jørgensen, JB, 1953. The Eskimo Skeleton.Meddelelser om Grønland; 146(2):1-54 [Dissertation].

[141] Lynnerup N, Lynnerup O, Homøe P, 1992. A computer program for planimetric analysis of digitized images. Comput Biol Med.; 3:207-17.

[142] Milner GR, Wood JW, Boldsen J, 2000. Paleodemography. In: Biological Anthropology of the Human Skeleton (Katzenberg MA \& Saunders SR, eds.). Wiley-Liss, New York. Pp 467-498.

[143] Boldsen JL, Milner GR, Konigsberg LW, Wood JW. 2002. Transition analysis: a new method for estimating age from skeletons. In: Hoppa R, Vaupel J, editor. Paleodemography: age distributions from skeletal samples. Cambridge: Cambridge University Press. p 73-106.

[144] Konigsberg LW, Herrmann NP, wescott DJ, Kimmerle EH, 2008. Estimation and Evidence in Forensic Anthropology: Age-At-Death. Journal of Forensic Science, 53(3): 541-557

[145] Lynnerup N, Clausen M-L, Kristoffersen AM; Steglich-Arnholm, 2009. Facial recognition and laser surface scan: a pilot study. Forensic Science, Medicine and Pathology, 5(3): 167-173. 